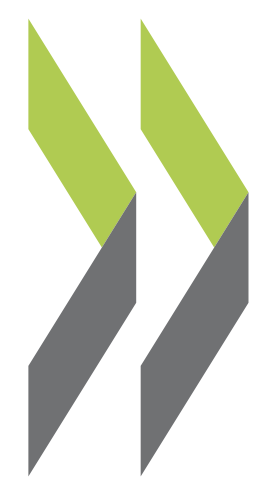

OECD Local Economic and Employment Development (LEED) Papers 2010/17

\title{
Building Flexibility and Accountability into Local Employment Services: Country Report for Canada
}

\section{Donna E. Wood}




\section{Building Flexibility}

\section{and Accountability into}

\section{Local Employment Services}

Country report for Canada 


\section{Building Flexibility}

and Accountability into

\section{Local Employment Services}

Country report for Canada 
TABLE OF CONTENTS

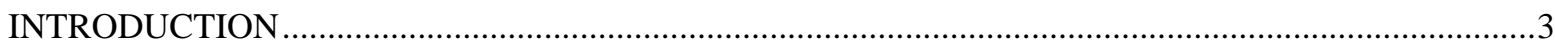

CONCEPTUAL FRAMEWORK: BALANCING FLEXIBILITY WITH ACCOUNTABILITY ..................6

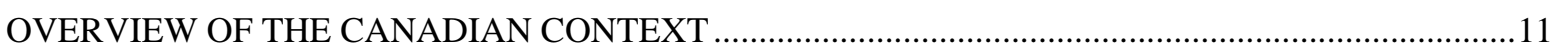

FLEXIBILITY AT THE LOCAL LEVEL: THE ALBERTA CASE STUDY ............................................26

FLEXIBILITY AT THE LOCAL LEVEL: THE NEW BRUNSWICK CASE STUDY .............................40

KEY POINTS FROM THE EXAMINATION OF ACCOUNTABILITY AND FLEXIBILITY IN

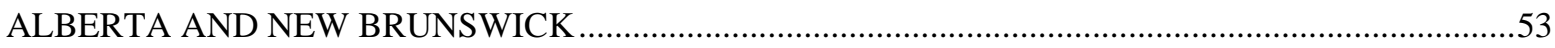

ACCOUNTABILITY AND FLEXIBILITY IN NINE OTHER CANADIAN PROVINCES AND

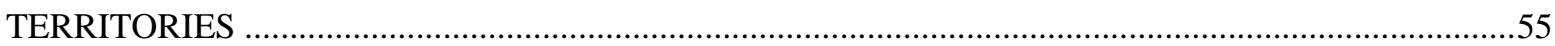

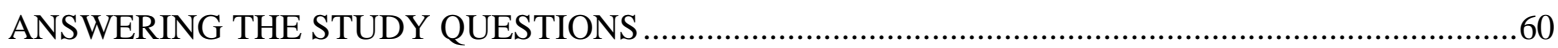

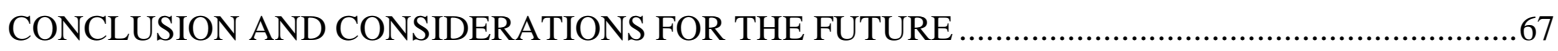

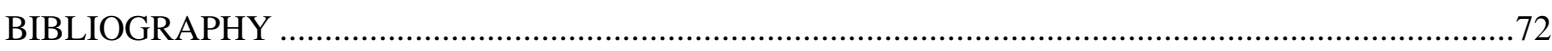

ANNEX A. VENICE ACTION STATEMENT ON ENHANCING FLEXIBILITY IN THE

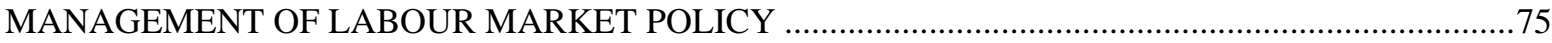

ANNEX B. METHODOLOGY FOR ASSESSING LOCAL FLEXIBILITY IN LABOUR MARKET

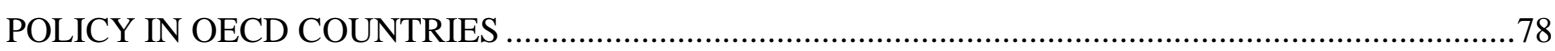




\section{INTRODUCTION}

1. Decentralisation and enhanced local governance of employment and skills development policy has long been promoted by the Organisation for Economic Co-operation and Development (OECD) as a key mechanism to boost economic growth and create jobs (OECD, 2003). Decentralisation can be either administrative or political. Administrative decentralisation occurs when managers in regional and local offices receive greater operative flexibility in implementing national policy objectives. Political decentralisation occurs when powers to design and implement policies are devolved to semi-autonomous sub-national governments with their own elected leadership. In these latter cases the relationship between central and sub-national authorities is less hierarchical and more negotiated.

2. Decentralisation is not an end in itself but is intended as a way to achieve a more coherent policy approach as well as ensure that programmes can be customised to individual and local needs and circumstances. Irrespective of the type of decentralisation, for labour market programmes to perform well in reducing unemployment and making labour markets more effective, there is a need for increased reliance on inter-organisational networks or partnerships at the regional or local level, especially between labour market policy actors and their social and economic development partners (Mosley, 2009).

3. Canada is a federation. Before 1996, Canada's national employment service was managed and delivered in conjunction with the national unemployment insurance programme through a network of over 500 federally managed offices across the nation. In the 1980s and 1990s Employment and Immigration Canada began to forge closer regional and local partnerships through administrative decentralisation of decision making to their regional directors, who operated out of provincial capitals across Canada. This turned to political decentralisation in 1996 when the Government of Canada offered to devolve responsibility for active employment measures for recipients of federal Employment Insurance (EI) benefits to interested provincial/territorial governments. Re-alignment of responsibilities in active labour market programming had also been an objective of both orders of government in previous failed attempts to change the Canadian constitution.

4. Political decentralisation in Canada was realised through bilateral Labour Market Development Agreements (LMDAs) that involved a transfer of federal staff, assets and funding to provincial/territorial governments (henceforth known as P/Ts) ${ }^{1}$. Starting with the province of Alberta in 1996, it has taken over

This was done in conjunction with a major reform to the Unemployment Insurance programme, which was re-branded as Employment Insurance (EI). Although active measures could be provincially delivered, federal offices continue to deliver passive Employment Insurance benefits (called EI Part 1). 
14 years for all $13 \mathrm{P} / \mathrm{T}$ jurisdictions to enter into LMDAs with the Government of Canada ${ }^{2}$. As of 2010, there are relatively symmetrical active labour market services designed and delivered under P/T government control available across Canada. In 2007, Labour Market Agreements (LMAs) were developed to complement LMDAs. LMAs provide P/T governments with additional federal funding to 2014 to support skills development for unemployed individuals who are not eligible for EI benefits and employed individuals who are low-skilled. In response to the economic downturn that began in 2008, these agreements were further enhanced in 2009 for two years through Canada's stimulus measures, the Economic Action Plan, which amended the LMDAs and LMAs in order to provide additional supports to the newly unemployed.

5. Even with devolution, federal or national governments limit the flexibility they hand down for two reasons - to achieve national objectives, and to maintain accountability (Froy and Giguère, 2010a). The purpose of this report is to assess how the new governance regime put in place in Canada (particularly with respect to the LMDAs and LMAs) has influenced the flexibility available to local and regional labour market offices and the ways in which they are held accountable. The focus is on active labour market policies, that is programmes designed to improve access to the labour market and jobs, develop job related skills, and promote more efficient labour markets (OECD, 1994). They are "active" in contrast to "passive" measures, such as unemployment insurance, social assistance and other financial transfers designed to mitigate the hardships of the unemployed. The report draws upon the extensive international and comparative work that the OECD and others have undertaken on this issue over the past decade.

6. Canada's almost 34 million people occupy the second largest land mass in the world, organised into ten provinces and three territories. Two of these provinces - Alberta and New Brunswick - are the subject of case studies in this report. Between August 2009 and January 2010, 26 interviews with senior government officials and service delivery providers in Alberta, New Brunswick and Ottawa were conducted and analyzed; 28 e-surveys from regional and local staff in the participating provinces were administered and assessed; two study tours involving six roundtables in Edmonton, Wetaskawin, Moncton and Miramichi with almost 100 provincial government staff and their community partners were organised and held; and applicable federal and provincial documents and agreements were reviewed. In all cases a structured framework developed by the OECD was used by the Canada country expert to ensure consistency in the questions asked of those working in the sector. This consistent structure has allowed for comparisons to be made between provinces within Canada, and will ultimately be used for making comparisons between Canada and the other OECD countries.

7. One of the most salient characteristics of Canada is regional diversity - geographic, economic, labour market and cultural. In such a large country distances are great and there is a sense of distance from the capital Ottawa. There are considerable wealth disparities between provinces/territories which often results in competing interests. One source of diversity in Canada comes from Québec, which, in addition to language has its own history and culture. Another is Canada's growing Aboriginal population with its distinctive culture and language. In order to make this Canada country report more representative of all signed co-managed agreements where the federal government retained responsibility for programme design and delivery. 
parts of Canada, the OECD case study research (with its focus on Alberta and New Brunswick) was complemented with a scan of the programme and service delivery environment in the nine jurisdictions that did not participate in the OECD case study research. Although not considered to the same depth, these findings, as well as the existing literature on labour market policy in the Canadian context, have been incorporated into this Canada country report. 


\section{CONCEPTUAL FRAMEWORK: BALANCING FLEXIBILITY WITH ACCOUNTABILITY}

\section{Flexibility}

8. Flexibility is "the possibility to adjust policy at its various design, implementation and delivery stages to make it better adapted to local contexts, actions carried out by other organisations, strategies being pursued, and challenges and opportunities faced" (Giguère and Froy, 2009, pp. 13-14). Bruce (2009) clarifies that it is not flexibility in the performance of the labour market that is the focus, but the flexibility of management regimes which oversee and influence how labour market policy is planned, designed and delivered.

9. Flexibility in labour market policy is needed so that service providers can tailor services to take individual and local circumstances into account. Standardised and strictly regulated policy programmes leave little room for frontline workers to manoeuvre in the actual service delivery process, to effectively tackle local employment challenges (Giguère and Froy, 2009). For the OECD, it is not as important whether federal or provincial/territorial governments are in charge of employment policy, but that flexible policy is available to actors at various levels of the system to allow for local orientation of programmes in a manner that meet the needs of citizens and addresses contemporary economic challenges. In the Canadian context, this means that $\underline{\mathrm{P} / \mathrm{T}}$ flexibility through devolution is not enough - this flexibility must be passed on to the sub-provincial/territorial (referred to in this report as regional) level as well as to the local (or city/town) level ${ }^{3}$. Regional and local flexibility is important as it leads to more strategic, responsive and customised active labour market programmes, which in turn directs more training resources to those who need it, resulting in a positive effect on employment rates (Giguère and Froy, 2009). In this report flexibility in labour market policy is therefore considered at three levels beyond Ottawa - that is at the provincial/territorial, regional and local level, with a particular focus on the regional and local level.

10. Through their research, the OECD has identified a number of "flexibility indictors" including:

1. Strategic approach, programme goals and programme design: Do regional and local offices have input into the design of policies and programmes? Are they consulted? Are they free to determine the programme mix and adapt programmes? Can they design local employment strategies?

2. Client eligibility: Do regional and local offices choose the target groups that they will work with? Who decides who can be served?

\footnotetext{
${ }^{3}$ For example in the Province of Alberta in Canada, Alberta Employment and Immigration (AEI) has 6 regional offices and 59 local delivery sites across the province.
} 
3. Performance measures and targets: To what extent are performance measures and targets centrally determined? Do they allow room for regional targets and flexibility in adapting to local circumstances? Are targets and indicators hierarchically imposed or negotiated with regional and local actors? Are sanctions imposed if targets are not met? Are regional and local offices benchmarked against each other?

4. Collaboration and partnerships: Can regional and local offices decide who they collaborate with locally? Is collaboration recognised or rewarded? Are regional and local offices involved in co-delivery arrangements?

5. Budgets and financing: Are the resources available to regional and local operating units adequate? Do regional and local actors have flexible global budgets or line item budgets for active measures? Are they free to allocate resources flexibly between budget items?

6. Staffing and Outsourcing: To what extent are regional and local organisational units free to hire, recruit, train and pay personnel and assign them to tasks at their own discretion? Are they free to decide what services to contract out to external providers?

11. In tension with flexibility is an acknowledgement that national policy goals matter and that there are trade-offs between decentralisation and accountability. In most countries, labour market policy is considered as a national priority that requires national co-ordination. Although decentralisation may enhance programme outcomes, it may also have unintended negative effects, for example, uneven quality in service delivery, potential conflicts of interest, duplication of effort, problems in performance accountability due to the number of organisations involved, and difficulties in achieving standardisation in labour market and performance data. In general, based on discussions in other OECD countries, administrations sometimes have concerns that local level actors may be less able and experienced than their national counterparts and more inclined towards local protectionism. Decentralisation may also conflict with notions of equal citizenship and equal application of the law, especially within countries with a strong tradition of social rights (Mosley, 2009).

\section{Accountability}

12. Given this context, systems of accountability are as important as flexibility. Accountability is essentially a system of checks and balances designed to protect the public interest and minimise the potential for abuse of power or spending. The purpose of an accountability regime is not to eliminate the possibility of failure, but to ensure that public money is spent for the purpose intended, that audit trails are maintained, and that there is some mechanism to measure or report on the impact of the spending (Bruce, 2009).

13. Mosely (2009, p. 86) identifies four dimensions of accountability that are considered important by governments: legal accountability (public agencies being expected to act on the basis of the rule of law and in conformity with applicable regulations), fiscal accountability (correctness and efficiency in the use of finances), performance accountability (output-oriented effectiveness and efficiency), and public accountability (responsiveness to the needs of citizens and other stakeholders). He identifies the particular accountability challenges in multilevel governance systems such as Canada when the leverage of national 
authorities over $\mathrm{P} / \mathrm{T}$ governments is based on the national government providing funding to $\mathrm{P} / \mathrm{T}$ governments (in Canada called the federal spending power) to accomplish national objectives.

14. Klassen and Wood (2010) provide a slightly different perspective on accountability considered within the context of a federal system of governance, and assess accountability in Canadian labour market policy using the following dimensions:

1. Democratic accountability: To what degree have citizens and stakeholders been involved and are the initiatives in accordance with the needs and interests of social groups or society as a whole? Have governments reported in a transparent fashion to citizens?

2. Political accountability: To what degree have legislatures been involved and do the activities adhere to federal principles?

3. Administrative accountability: How effectively has the permanent executive managed the programme in accordance with the established rules and procedures? What is the process for establishing the rules and procedures in the first place and how effective is it?

15. Bar Cendon (2000) argues that in the recent past we have witnessed a move in administrative accountability towards the use of strategic goals and objectives, establishing budgets, and setting minimum guidelines and rules. McGarvey (2001, p. 23) notes that to have effective accountability measures in place there needs to be a concerted effort to involve "civil society" - beyond the bureaucracy - in defining the terms of accountability. This recognises that accountability is much more than establishing rules and norms, it is also about a shared responsibility between multiple partners for outcomes (Bruce, 2009). This however presents additional accountability complexity where each partner is accountable 1) to its own governing body 2) to the partnership and 3) to its local public. Clearly these accountability chains are not of equal status. For regional and local authorities, the accountability chain of their own governing body has priority and can therefore constrain their participation and commitment to any partnerships. In terms of federal-provincial/territorial (F-P/T) accountability in Canada, this also raises the question of to whom P/T governments are accountable when the funding for programming they deliver comes from the Government of Canada.

\section{Balance between Flexibility and Accountability in Canada Pre-devolution}

16. In 2008, the OECD assessed the hierarchy within the public employment service of OECD countries, and considered which countries had the most flexibility in the management of labour market programmes for those eligible for employment insurance benefits. The results were discussed at a high level conference attended by Ministers, Deputy Ministers and senior officials from OECD countries in Venice in April 2008. A copy of the action statement agreed by participants at this meeting is included as Annex A to this report. Based on the information available to them at the time, the OECD concluded that, when it comes to flexibility at the local level, Denmark, Switzerland, the United States, Finland and the Czech Republic presented the highest degree of flexibility, while the United Kingdom, Spain, the Slovak Republic, Australia and Greece had the least flexibility. Canada's showing was in the middle of the pack. 
Figure 1. OECD Countries with the Most Local Flexibility in Labour Market Policy

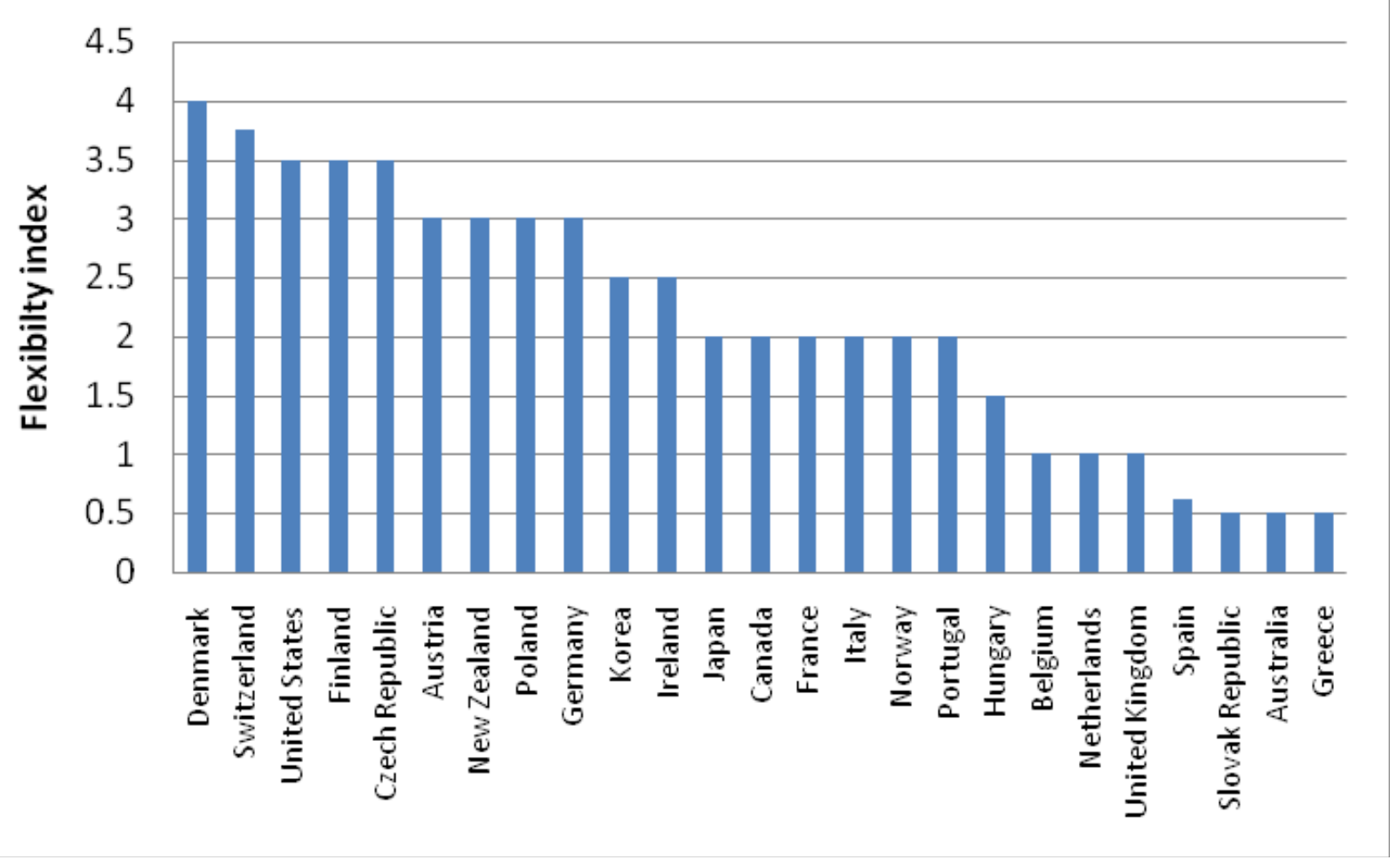

17. At the time the data was collected, only those Canadian P/Ts operating under co-managed LMDAs (18\% of the Canadian population) were included in the Canadian assessment. The report noted that local employment offices worked within relatively tight and restrictive legal accountability frameworks in those P/Ts where the Government of Canada still managed and delivered the programmes, and that final decisions for funding were often taken at national and P/T office levels, not at the local level. It was noted that devolved LMDAs with all jurisdictions were expected to create further flexibility and counter this prevailing federal accountability culture (Froy and Giguère, 2010).

\section{Study Objectives and Questions}

18. The current Canadian labour market governance regime under the LMDAs is very different from that assessed in the 2008 OECD research (Giguère and Froy, 2009). This follow-up OECD study presents an opportunity to reflect on Canada's ranking within the context of the relatively symmetrical LMDAs in place in all Canadian jurisdictions. Drawing on the detailed case studies in Alberta and New Brunswick as well as additional pan-Canadian information, this report attempts to answer the following questions:

1. What has changed with the implementation of the Labour Market Development Agreements starting in 1996 and the introduction of the Labour Market Agreements starting in 2007?

2. Where do regional and local offices have the most flexibility and where is there the least?

3. Do regional and local offices have enough flexibility to respond to local issues and challenges as well as the consequences of an economic downturn? 
4. Is there enough accountability to satisfy provincial/territorial, national and citizen policy concerns?

5. Are there forms of horizontal accountability (e.g. partnerships, boards, committees) that could substitute for vertical accountability over the longer term? 


\section{OVERVIEW OF THE CANADIAN CONTEXT}

\section{Canada's Particular Brand of Federalism}

19. Canada is a federal system of governance, set up in 1867 through a written constitution (the British North America Act) that initially involved an agreement between three British colonies (Canada now modern day Québec and Ontario - Nova Scotia and New Brunswick) who wished to form an economic union and protect themselves from American expansion. Over the past 143 years the country has expanded such that today it incorporates ten provinces and three territories. The key defining feature of a federation is that each order of government is sovereign within its area of jurisdiction and neither, acting alone, can change the constitution. The Canadian constitution divided powers, giving the federal government trade and commerce, foreign relations, defence, taxation, as well as the declaratory power, disallowance, and the residual power. Provincial (and later territorial) governments were assigned health care, education, property and civil rights, and natural resources. Immigration and agriculture were explicitly identified as concurrent.

20. Since provincial and territorial governments in Canada have significant autonomy, accountability relationships between federal and P/T governments are particularly challenging, especially when - as is the case with labour market policy - a conditional exchange of funds is involved. In 2008 the Treasury Board of Canada Secretariat developed specific guidelines on transfer payments to other orders of government ${ }^{4}$, taking into account respect for the jurisdiction and responsibilities of each order of government, and respect for the accountability of each order of government to their citizens. The guidelines identify mandatory elements that any agreements must include including a description of the activities, eligible recipients, type and nature of expenditures, payment formula, and monitoring and reporting mechanisms. On the other hand they also suggest that, to the greatest extent possible, reliance should be placed on the accountability regimes of P/T governments, including their audit, evaluation and process for direct reporting to citizens.

21. There is no mention of labour market policy in the division of powers under the British North America Act, and from the country's beginning both federal and provincial (and later territorial) governments have been involved. Although the federal government has responsibility for overall macroeconomic policy, post-confederation most policy instruments relating to human resource development were considered to be under provincial (and later also territorial) jurisdiction ${ }^{5}$. As a result, the various

See $w w w . t b s$-sct.gc.ca/pol/doc-eng.aspx?id=14208\&section=text\#sec6.

Under Section 93 of the 1867 BNA Act, making laws with respect to education (and, by inference, training), hospitals, asylums, charities, and eleemosynary institutions are exclusive powers of provincial legislatures. 
employment centres, labour exchanges, relief measures, and vocational and technical education programmes established before the Second World War were set up by provinces and supported by federal conditional grants (Hunter, 1993).

22. Over time, these employment services came under increasing criticism, with failings attributed mostly to divided jurisdiction and joint administration. There was also federal-provincial wrangling over federal relief funds (Canada, 1940). Concerned over the mobility of labour and capital in a federal state, pressure built on the federal government to intervene directly in the labour market. However, it took the extraordinary conditions of the Depression and the inability of cash strapped provinces, territories and municipalities to provide adequate relief to the unemployed to convince provinces and all political parties to agree to an amendment to the British North America Act $^{6}$. By the end of the 1930s, all provinces had agreed to strengthen federal jurisdiction in labour market policy by allowing the Government of Canada to run a contributory Unemployment Insurance (UI) scheme, including a national employment service and the provision of training. At the time, it was felt that these two functions were inextricably linked, with an efficient employment service providing the foundation for the Unemployment Insurance scheme ${ }^{7}$. Despite the constitutional amendment, provinces and territories retained responsibility for the long-term unemployed through social assistance and other social programmes.

23. Over the ensuing years the federal government expanded its delivery network across the nation, providing both Unemployment Insurance as well as active employment measures. They also leveraged training for federal UI claimants from P/T governments. At the same time as the federal government expanded its role in the sector, the larger and more affluent provinces developed similar employment programmes for client groups and industrial sectors that met their particular priorities or were felt to be underserved by the federal programmes. This presented opportunities for federal and P/T governments to renew discussions over which order of government should design and deliver active employment measures (Lazar, 2002). Of particular significance were decisions taken by most P/T governments in the 1990s to expand employment services and supports for social assistance clients as a result of rising caseloads and costs. Many also started offering youth programming.

24. As a result of these activities, by the mid-1990s several P/Ts had established their own employment and career development services and increasingly argued that labour market policy could be more efficient and effective - and duplication eliminated - if decision making was closer to the local level (Bakvis and Aucoin 2000, Klassen 2000) ${ }^{8}$. The OECD discourse on the importance of decentralisation of labour market policy coincided with a federal imperative to demonstrate flexible federalism as a result of

In 1933, nearly a quarter of the country's labour force was unemployed and an estimated 15 percent of the population were on some form of relief (Banting, 2005, p. 97).

This interpretation has recently been confirmed by the Supreme Court of Canada, which in Confederation des syndicats nationaux vs. the Attorney General of Canada on December 11, 2008 confirmed that active employment measures fall within the legislative authority of the Government of Canada. See http://lexisnexis.ca/documents/Arvida-en.pdf .

It is noteworthy that there is very limited municipal involvement in active labour market policy in Canada, except in Ontario where the province has devolved social assistance responsibility to municipal governments. 
the 1995 Québec sovereignty referendum. In May 1996, the Government of Canada through a Ministers' press release committed to withdraw from labour market training and offered to transfer federal Employment Insurance (Part II) funding, staff and assets to provincial and territorial governments interested in assuming an expanded role ${ }^{9}$.

\section{The Labour Market Development Agreements}

25. Although constitutional re-alignment in labour market policy had been proposed in the Charlottetown Accord, the defeat of the accord in a 1992 referendum meant that administrative, rather than constitutional, devolution would be pursued. The LMDAs, in effect, acted as a substitute for formal constitutional reform, what Poirier (2003) identifies as "para-constitutional engineering". Each agreement was negotiated bilaterally, with the first round of agreements in place in seven jurisdictions by 2000 , Ontario in 2005, and the remaining five jurisdictions between 2008 and 2010. The annual federal allocation to the LMDAs is $\$ 1.95$ billion, funded by employer and employee contributions to the Employment Insurance account.

26. The bilateral agreements are largely similar with Ottawa controlling how much money is available, how funds can be used, and who can be served. Each agreement has what is referred to as a "me too" clause to ensure equality of treatment, and to reassure those P/Ts that negotiated the first agreements that preferred treatment obtained through later agreements was also applicable to them.

27. Through the LMDAs, P/T governments agree to provide Employment Benefits and Support Measures (EBSMs) similar to those outlined in the EI Act. Employment Benefits (for example skills training, wage subsidies etc.) are only available to EI clients and reach back claimants (those that received EI benefits within the past three years or past five years if it was a maternity or parental claim). Support measures (for example employment assistance services) are available to all unemployed Canadians, not just EI clients.

28. P/T governments were motivated to sign a LMDA due to the opportunity it presented to have more control - with the necessary federal funding - over the design, management and delivery of all active measures within their jurisdiction. It is now P/T governments, not the Government of Canada, which has authority for the initiating and integrating role. The agreements allow P/Ts to align federally funded programmes with $\mathrm{P} / \mathrm{T}$ priorities and programmes, and realise economies of scale through combining federal and P/T resources. Many P/Ts used the opportunity of taking on an LMDA to reconfigure how they structured labour market services within their $\mathrm{P} / \mathrm{T}$, including relationships with their post-secondary education, social assistance and economic development programmes. Service delivery providers within each P/T that used to face two government funding bodies with different goals, programme parameters, client eligibility requirements, reporting requirements, operational targets and decision-making processes are now presented with a unified and coherent government stance under P/T control.

\footnotetext{
${ }^{9}$ It should be noted that the offer to withdraw from the purchase of training was never intended to include training for Aboriginal people as well; the Government of Canada advised all P/Ts when the offer to devolve training was made that it would retain funding for the training of Aboriginal people.
} 


\section{The Labour Market Agreements}

29. The Government of Canada's Budget 2007 introduced funding for Labour Market Agreements (LMAs). These agreements provide P/T governments with $\$ 500$ million annually for six years to support skills development for unemployed individuals who are not eligible for EI benefits and employed individuals who are low-skilled. There are a wide variety of programmes that P/Ts can offer with the federal funding. The purpose of the LMAs is thus to enhance P/T employment and training programming - including an ability to serve groups previously not eligible under the LMDAs - using federal resources. The agreements specify that the federal funding must be incremental, and cannot be used to make up for $\mathrm{P} / \mathrm{T}$ cutbacks in the same area. The LMAs are funded from the federal Consolidated Revenue Account, are not founded on a particular body of legislation (like the EI Act), and are targeted to end in 2014. Unlike the LMDAs, where funding was distributed based on historical allocations and labour market variables, LMA funding is distributed on a per-capita basis.

30. In response to the economic downturn and the significant increase in the unemployment rate, the 2009 federal budget committed over two years an additional \$1 billion to the LMDAs and an additional \$500 million, delivered under the Strategic Training and Transition Fund (STTF) part of the LMA framework, targeted to those affected by the economic downturn and those seeking to retrain or upgrade their skills to keep employment. The money delivered under the STTF was for all unemployed Canadians, regardless of EI status. These additional commitments and the conditions under which the funding is allocated are outlined in the Economic Action Plan. In this case funding is distributed based on the jurisdiction's share of the unemployed.

\section{The Federal Role Post-devolution}

31. With the provinces and territories responsible for delivery of labour market programmes and services, the federal role is now focused primarily on providing funding; ensuring accountability, evaluation and national policy priorities; ensuring similarity in service provision across the country; and delivering pan-Canadian programming and services. The current federal department responsible for these activities is Human Resources and Skills Development Canada (HRSDC). The federal funding role is most significant with respect to the LMDAs and LMAs. However, they also contribute to cost-shared P/T programmes for older workers through the F-P/T Targeted Initiative for Older Workers (TIOW) and for disabled persons through the Labour Market Agreement for Persons with Disabilities (LMAPD). All told, when the TIOW and LMAPDs are added to the LMDAs and LMAs, there are 49 bilateral F-P/T agreements in place that govern labour market adjustment programmes in Canada. Each of the bilateral agreements have defined policy parameters, accountability frameworks and "envelope" federal funding allocations which P/Ts must track and account to HRSDC for (as per Treasury Board regulations), to ensure that federal funds are spent on initiatives for which they were intended. The parameters around these bilateral agreements provide HRSDC with the ability to establish priorities in the policy domain, and a way to steer provincial and territorial activities to promote national, pan-Canadian interests (Wood and Klassen, 2009). Regarding programme design, the EI Act states that the Government of Canada works in concert with the provinces and territories. For instance, the EI Part II Activities Accountability Framework ensures that similar employment benefits and support measures are provided by each province and territory under the LMDAs. Furthermore, there are provisions in the LMDAs for the exchange of information and mutual target setting between the federal government and the P/Ts. 
32. Post-devolution HRSDC has also retained responsibility for national aspects of labour market development including labour mobility, the national Job Bank, labour market information, Sector Councils and research and innovation. Despite federal acknowledgement that P/T governments have the primary responsibility for the design and delivery of active labour market programmes, the Government of Canada continues to design and directly deliver employment supports for selected vulnerable groups.

33. Disabled persons are served directly thought a federal programme called the Opportunities Fund, which assists them in preparing for, obtaining and keeping employment or self-employment, thereby increasing their economic participation and independence. For Aboriginal people, starting in 1996, the Government of Canada began to shift the delivery of labour market programs and services to Aboriginal groups. Currently, HRSDC implements a suite of programs to support the participation of Aboriginal people in the Canadian economy, which focuses on demand-driven skills development and training through partnerships with the private sector and other levels of government.. The federal government's primary labour market programme for Aboriginal people is the Aboriginal Skills and Employment Training Strategy (ASETS), which funds a network of Aboriginal organizations who provide or support skills development and training activities for Aboriginal people. The Skills and Partnership Fund (SPF) is a project-based programme that is intended to support innovative projects, new approaches to employment services, and address systemic gaps in service delivery. The Aboriginal Skills and Employment Partnership (ASEP), is a project-based programme that promotes increased participation of Aboriginal people in large scale economic development opportunities.. HRSDC also continues to be extensively involved in the funding, design and delivery of labour market adjustment measures for youth through the Youth Employment Strategy. This includes Skills Link, Career Focus, Canada Summer Jobs and the operation of Service Canada Centres for Youth.

34. In the 2007 federal budget, the Government of Canada offered to explore the feasibility of transferring the funding and delivery of federal youth, older worker and disability programming to P/T governments. However, to date no action has been taken nor, according to federal officials, are any plans underway. The political nature of this remaining federal programming makes further devolution in this area very challenging.

35. These remaining federal labour market programmes are designed by HRSDC in Ottawa but delivered at the regional and local level by Service Canada. In 2005 the Government of Canada severed HRSDC's service delivery function from the policy role by establishing a single point of access to a wide range of federal government services and benefits. The core services provided by Service Canada are those previously provided by HRSDC - access to Employment Insurance benefits, old aged security, Canada Pension Plan, social insurance numbers, Canada Child Tax Benefit, etc. but now also include non-labour market related services such as passports and HST/GST credits.

\section{Pan-Canadian Interaction and the Role of Non-government Actors}

36. With respect to multilateral relationships, the key institution used for management of F-P/T and interprovincial interaction in employment policy in Canada is the Forum of Labour Market Ministers (FLMM), set up in 1983 to promote interjurisdictional co-operation. Meetings occur at the Minister, Deputy Minister, senior official, and working-levels with representatives from the federal government and the 13 provinces and territories. Three officials' working groups - labour market information, labour 
mobility, career development (plus an ad hoc group on foreign credential recognition) - are active ${ }^{10}$ and beginning in 2008 one to two promising "best practice" workshops a year have been held. These have provided an opportunity to share lessons, evaluation data, compare flexibility in respective agreements, etc. In addition, federal, provincial and territorial Ministers Responsible for Social Services work collaboratively to ensure that persons with disabilities can participate successfully in the labour market. ${ }^{11}$. Collaborative work which has been carried out through these multilateral forums include information sharing at multilateral best practices workshops, cooperation on areas to improve labour market mobility and the integration of recent immigrants, (i.e. foreign credential recognition), labour market information, etc.

37. In terms of business, labour and civil society participation in the policy domain, each P/T manages this in the way they deem most appropriate and, as will see later in this report, Alberta and New Brunswick have extensive partnerships with economic development agencies, employer associations, postsecondary institutions, other governments, as well as community and Aboriginal organisations. In many $\mathrm{P} / \mathrm{Ts}$, labour market supports and services are delivered by third party agents through contractual arrangements as opposed to P/T government staff. The degree to which third party agents are involved in the policy domain varies considerably from one jurisdiction to another - for example, in Ontario it is estimated that there are over 5000 service providers funded through the LMDAs and LMAs. New Brunswick, on the other hand, estimates that $80 \%$ of services are provided in house by provincial government employees.

38. With respect to the involvement of non-government actors on a pan-Canadian basis, the EI programme overall (of which the LMDAs are a part) is governed by the Employment Insurance Commission, which has four members: two representing the interests of government and one each representing the interests of workers and employers. The Commission produces an annual EI Monitoring and Assessment Report that is tabled in Parliament that provides detailed information on the LMDAs ${ }^{12}$. The Government of Canada has also established 35 national sector councils and related organisations involving business, labour, educational institutions, governments and professional associations to assess future employment patterns, skills requirements and training practices and to develop measures to help employers and workers meet and adapt to the changing needs of each occupational sector. From 20042009 federal funding was also provided to the Canadian Council on Learning (CCL), an independent, nonSee $w w w . f l m m$-cds.ca/english/View.asp? $x=1103$, and www.flmm-lmi.org/english/View.asp? $x=1$.

Since the drafting of this report, the Government of Canada has focused particularly on refining accountability and performance measures, examining ways to eliminate barriers to full participation for persons with disabilities, and sharing information on best practices in negotiations with the $\mathrm{P} / \mathrm{Ts}$ on LMAPD renewal. The F-P/T Multilateral Framework for the LMAPDs (established in 2004) reaffirms the commitment to provide programs and services to improve the employment situation of persons with disabilities.

See $w w w . r h d c c-h r s d c . g c . c a / e n g / e m p l o y m e n t / e i / m o n i t o r i n g \_a s s e s s m e n t / i n d e x . s h t m l$.

AHRDS was replaced in 2010 by the Aboriginal Skills and Employment Training Strategy (ASETS) and the Skills and Partnership Fund (SPF). 
profit corporation set up to promote and support research to improve all aspects of learning. One of their knowledge centres focused on work and learning. Federal funding for the CCL ended in 2010.

\section{Governance of Labour Market Policy in Canada Post-devolution}

Table 1. : Governance of Labour Market Programmes in Canada Post-Devolution

\begin{tabular}{|c|c|c|}
\hline $\begin{array}{l}\text { Activities taken by } \\
\text { provinces/territories }\end{array}$ & $\begin{array}{l}\text { Activities coordinated between the } \\
\text { federal level and the } P / T \text { s }\end{array}$ & Federal only activity \\
\hline $\begin{array}{l}\text { Income support } \\
\text { Social assistance } \\
\text { Disability programmes } \\
\text { Workers' Compensation } \\
\text { Services and supports } \\
\text { Youth programmes } \\
\text { Apprenticeship training and } \\
\text { certification } \\
\text { Basic and skills training } \\
\text { Disability supports } \\
\text { Regulation of trades and professions } \\
\text { Post-secondary education } \\
\text { institutions }\end{array}$ & $\begin{array}{l}\text { Labour Market Development } \\
\text { Agreements (El recipients) } \\
\text { Labour Market Agreements } \\
\text { (unemployed \& underemployed) } \\
\text { Targeted Initiative for Older Workers } \\
\text { Labour Market Agreement for Persons } \\
\text { with Disabilities } \\
\text { Labour market Information } \\
\text { Labour mobility } \\
\text { Red Seal Programme and } \\
\text { Interprovincial Standards } \\
\text { Career Development Services } \\
\text { Foreign credential recognition }\end{array}$ & $\begin{array}{l}\text { Income support } \\
\text { Employment Insurance (EI) } \\
\text { Canada Pension Disability } \\
\text { Services and supports } \\
\text { Opportunities Fund for Persons } \\
\text { with Disabilities } \\
\text { Youth Employment Strategy } \\
\text { Aboriginal Skills and Employment } \\
\text { Partnership } \\
\text { Aboriginal Skills and Employment } \\
\text { Training Strategy } \\
\text { Skills and Partnership Fund } \\
\text { Apprenticeship Grants } \\
\text { Sector Council Programme }\end{array}$ \\
\hline
\end{tabular}

39. The focus of this study is on the centre part of this diagram, that is the F-P/T relationship and the degree to which $\mathrm{P} / \mathrm{T}$ governments and their regional and local arms have sufficient flexibility while also providing accountability to the Government of Canada for the funding provided.

\section{Federal-Provincial/Territorial Accountability Relationships}

40. The Report on Plans and Priorities is HRSDC's annual planning and priority document. Their key goal related to this study is a skilled, adaptable and inclusive labour force and an efficient labour market. The plan contains five performance indicators as well as defined targets for this broad goal. It highlights that F-P/T partnerships are essential to the Department's success in meeting these objectives. The LMA is identified as having a "robust accountability framework" and, while performance indicators are noted, there are no targets in the HRSDC plan as these are expected to be set by P/Ts. This contrasts with the LMDA portion of the plan which identifies both performance indicators as well as pan-Canadian targets.

41. The LMDAs and LMAs are programme-specific transfer agreements that, in effect, provide P/T governments with federal funding to design and deliver provincial labour market programmes. The agreements are therefore all conditional - that is, funding is dependent upon provincial/territorial governments fulfilling the terms of the agreements, including reporting to the Government of Canada. 
Under the LMAs, funding will be withheld if audited statements are not provided, and the agreements outline dispute resolution mechanisms. Box 1 below outlines the accountability regimes within the LMDA and LMAs.

42. The LMDAs are authorised by and governed by the federal Employment Insurance Act as introduced in 1996 and amended from time to time. Part I of the Act provides detailed information on what are called "unemployment benefits" while Part II focuses on what are called "employment benefits, support measures and national employment service". Sections 57, 62 and 63 of this legislation provide the authority for the Canada Employment Insurance Commission, with the approval of the Minister of HRSD, to work in concert with provincial and territorial governments and enter into agreements for the purpose of designing Employment Benefits and Support Measures (EBSMs), determining how they are to be implemented, and establishing the framework for evaluating their success. This to be done with a view to harmonization with provincial/territorial employment initiatives, co-operation and partnerships with other governments, employers, community-based organisations and other organisations, and flexibility to allow significant decisions about implementation to be made at a local level (Canada, 1996).

43. Unlike the LMDAs, the LMAs are not associated with specific federal legislation, but are authorised by Ministerial authority to enter into agreements for a variety of purposes.

44. The Economic Action Plan built on the LMDAs and LMAs to provide additional funding in the context of the economic downturn. As a result, there were additional accountability provisions for this funding, primarily related to reporting. P/Ts are expected to include the results attributable to the additional funding in their annual reports. Planning for the increased funding as well as the results is to be reported separately. The Government of Canada used this information to prepare and table quarterly reports to Parliament that were publicly released.

\section{Box 1. Accountability regimes for the LMDAs and LMAs}

The accountability regime in the LMDAs focuses mostly on the legal, fiscal and administrative aspects of accountability, with the following key features:

- The programmes to be offered (called EBSMs) are to be similar to and consistent with the purpose and guidelines of Part II of the EI Act. There is a federally developed EI Part II Activities Accountability Framework that describes the employment benefits (targeted wage subsidies, targeted earnings supplements, self employment, job creation partnerships and skills development), support measures (employment assistance services, labour market partnerships and research and innovation) and their objectives in some detail.

- There are defined criteria as to who can be served through the agreements. For employment benefits only $\mathrm{El}$ and reach-back clients can be served; for support measures the criteria is more open to include the unemployed more generally and sometimes even those who are employed and facing a loss of employment.

- In terms of reporting, each agreement requires that P/T governments provide the Government of Canada with an annual plan three months before the beginning of a fiscal year, or alternatively with a breakdown of the amounts it intends to allocate to different elements of the EBSMs. There is no requirement that provinces release this plan to their citizens. P/Ts are also expected to submit to Canada an audited financial statement setting out costs incurred in respect of each EBSM. The El legislation used to require the El Commission to release an Annual EI Monitoring and Assessment report; however, it is now at the request of the Minister. The parties agree to an exchange of information and data on active El claimants and other El clients. The Government of Canada uses this information to develop and release an annual EI Monitoring and Assessment report that reports on all elements of El reform. 
- There are three agreed on indicators for measuring the results of the EBSMs: a) the number of active El claimants that access benefits and measures; b) returns to employment of El clients, with an emphasis on active EI claimants; and c) savings to the El account. P/Ts are expected to establish, in co-operation with the Government of Canada, mutually agreed results targets at the beginning of each fiscal year.

- $\quad$ The early agreements specified the establishment of a joint F-P/T process to support and oversee evaluations of the $\mathrm{P} / \mathrm{T}$ programmes. Later agreements provided for a joint year two review and evaluations managed and funded by the P/T, or joint evaluations funded by Canada. Most agreements establish a joint F-P/T management committee as a forum to resolve issues, discuss annual results targets and annual plans, oversee evaluations etc. The committees usually meet twice a year or more frequently, and operate on a consensus basis.

The key accountability provisions of the LMA agreements are as follows:

- There are a range of programmes that provinces and territories can choose to offer ranging from skills training to employment counseling to making labour market connections. Ineligible activities are limited to passive income support and core costs for educational institutions (including curriculum development, instruction and equipment in training institutions). There is no prescribed list identified in federal legislation that requires a "test of similarity".

- $\quad$ Eligible recipients are identified as unemployed individuals who are not El eligible as well as employed individuals who are low skilled. They can be from any vulnerable group the P/T deems appropriate, including social assistance recipients, Aboriginal peoples, new labour market entrants, immigrants, and older workers.

- There is a defined accountability framework consisting of:

1. Financial stewardship that would produce independently attested annual financial statement including attestation of incrementally.

2. Performance measurement of a common set of nationally comparable indicators building on the Labour market Development experience.

3. Reporting by P/Ts to their public on both the prior fiscal year as well as planning for the upcoming fiscal and national reporting by the Government of Canada.

4. Programme evaluation in each $\mathrm{P} / \mathrm{T}$ must include a high quality, peer reviewed evaluation to measure medium and long-term outcomes of programs. P/Ts are expected to develop and release a multiyear plan. They are expected to consult with key stakeholders in developing annual plans (including targets) to be made public. By October 1 of each fiscal year, each $P / T$ is expected to report annually to its citizens on the results of the programmes funded through the agreement. P/Ts must submit an audited financial statement demonstrating programme and administrative costs, surplus funds and the basis of accounting. They must also demonstrate that federal funding has been used to support programme activities that are in addition to, and not substituted for, those supported by normal P/T funding. The federal funding must be incremental, and cannot be used to make up for $\mathrm{P} / \mathrm{T}$ cutbacks in the same area. There is no exchange of client specific information, and no personal information is shared between governments. At the end of each fiscal year the federal government will report on the aggregate results.

- The agreements specify three beneficiary indicators, two service delivery indicators, and five outcome and impact indicators. Each jurisdiction is to provide Canada with the aggregate information on these indicators no later than five months following the end of each fiscal year. In Québec, the Emploi-Québec management results indicators are used instead. Annual targets for planned activities are expected to be included in the annual LMA plan. There is no requirement for targets to be mutually agreed with federal officials.

- A three stage dispute resolution process is outlined involving dispute avoidance, designated officials and then Ministers. Both parties agree to a joint year two review of the implementation of the agreement. Each $\mathrm{P} / \mathrm{T}$ agrees to carry out an evaluation of the impact and effectiveness of the eligible programmes and the funding provided. A P/T can undertake evaluations on its own or jointly with Canada. If joint, Canada will contribute $50 \%$ of the costs. Both parties agree to establish a joint committee to oversee the review and evaluations identified, discuss annual plans and reports, and identify ways to better integrate the delivery of programmes for Aboriginal peoples. 


\section{Degree of Flexibility that Provinces and Territories have to Manage Federally-funded Labour Market Programmes}

\section{Strategic Approach, Programme Goals and Programme Design}

45. Canada does not have an overarching strategic pan-Canadian labour market strategy. Instead federal officials look to political documents, throne speeches, ${ }^{13}$ and budgets for their strategic approach and programme goals when defining the F-P/T agreements in negotiation with the P/Ts. Although the EI Commission includes representatives of business and labour, there is no information publicly available that identifies how business, labour or P/Ts contribute to determining the parameters of Canadian EI programmes, including the active measures reviewed through this report. The Government of Canada supports 35 Sector Councils and related organisations involving business, labour, educational institutions, governments and professional associations tasked to identify and address human resources and skills issues in the sectors they represent. While it is unclear how these councils influence the delivery of provincial/territorial-delivered labour market programs, the products developed by sector councils such as sectoral labour market intelligence (including labour market forecasts and occupational standards for nonregulated jobs) inform public policy decisions and programme design.

46. In the LMDAs, the Government of Canada clearly identified the basket of programmes they wanted P/Ts to deliver. The programme parameters of Employment Benefits (targeted wage subsidies, targeted earnings supplements, self employment, job creation partnerships and skills development) and Support Measures (employment assistance services, labour market partnerships and research and innovation) are detailed through statements in both the EI legislation as well in HRSDC policy documents provided to $\mathrm{P} / \mathrm{Ts}$.

47. Each bilateral LMDA describes the benefits and measures to be offered in that jurisdiction, and identifies the various programme names that will be used in that particular jurisdiction. Each jurisdiction is further expected to identify how their programmes and services meet the "test of similarity" to programmes identified in the federal legislation. Table 2 outlines Alberta's test of similarity chart - each P/T is expected to provide something similar.

Throne Speeches in Canada outline overall government directions. Budgets are even more important as they provide additional details on government directions, including funding allocations. 
Table 2: Government of Alberta Employment \& Immigration (AEI) Provincial-Federal LMDA Programme Similarity Chart

\begin{tabular}{|c|c|c|}
\hline AEI Employment and Training Programmes & Programme Elements & $\begin{array}{c}\text { Federal Programme } \\
\text { Equivalent }\end{array}$ \\
\hline $\begin{array}{l}\text { Career Information } \\
\text { - Career and Employment Services help Albertans to } \\
\text { understand the labour market, to make informed career } \\
\text { decisions, develop realistic education, training and } \\
\text { employment plans and to prepare for, find and maintain work. }\end{array}$ & $\begin{array}{l}\text { - } \quad \text { Career \& Employment } \\
\text { Assistance Services } \\
\text { - Job Placement }\end{array}$ & $\begin{array}{l}\text { Employment Assistance } \\
\text { Services }\end{array}$ \\
\hline $\begin{array}{l}\text { Work Foundations } \\
\text { Provides full and part-time basic skills training to enable } \\
\text { individuals to pursue further job-related training and/or to find a } \\
\text { job and substantially improve their employment situation. }\end{array}$ & $\begin{array}{ll} & \text { Basic Skills } \\
\text { - } & \text { Academic Upgrading } \\
\text { - } & \text { English as an Additional } \\
\text { Language } \\
\text { University and Technical } \\
\text { Entrance Prep }\end{array}$ & Skills Development \\
\hline \multirow{4}{*}{$\begin{array}{l}\text { Training for Work } \\
\text { - Provides full and part-time occupationally-focused training } \\
\text { opportunities enabling individuals to get a job and substantially } \\
\text { improve their employment situation, adapt to changing labour } \\
\text { conditions or gain skills to sustain employment. }\end{array}$} & - Occupational training & Skills Development \\
\hline & $\begin{array}{l}\text { - Integrated Training } \\
-\quad \text { Immigrant Bridging }^{14}\end{array}$ & Job Creation Partnerships \\
\hline & - Workplace Training & $\begin{array}{l}\text { Targeted Wage Subsidy } \\
\text { (TWS) }\end{array}$ \\
\hline & - Self-Employment & Self-Employment \\
\hline $\begin{array}{l}\text { Workforce Partnerships } \\
\text { Ensures working Albertans continue to enhance their skills in } \\
\text { order to contribute to Alberta's economic growth or to respond } \\
\text { to skills shortages through collaborative efforts with industry, } \\
\text { community partnerships, employer groups, organisations, } \\
\text { industry sectors and municipalities with common labour market } \\
\text { needs. }\end{array}$ & - Labour Market Partnerships & Labour Market Partnerships \\
\hline
\end{tabular}

48. Although provincial/territorial governments were not consulted extensively about the specific programmes on offer for delivery through the LMDAs, the programmes and services identified are quite broad and, as a result, it has been relatively easy for P/Ts to match their programmes to those identified in

Immigrant Bridging Programs are a subset of Integrated Training programs and all components of Integrated Training policy apply to Immigrant Bridging Programs. Immigrant Bridging programs are focused on training immigrants with skills and/or education in a specific field so they can gain employment in their occupation or a related occupation. 
the federal legislation. P/Ts are fully free to determine the mix of programmes they will offer, indeed some provinces have chosen not to offer the full array of federally-identified programmes (for example Alberta has chosen to not offer traditional wage subsidy programs, preferring to characterise their programs as workplace training). They are also free to adapt the federal programmes as they see fit to their particular circumstances (within the confines of the test of similarity), and in most jurisdictions, programmes are available to all of their citizens through a combination of federal and P/T funding. Although annual LMDA plans are expected to be reviewed by F-P/T management committees, in none of this is there a sense that provinces/territories are seeking permission or approval from federal officials as to the programmes they plan to offer.

49. If there were any federal restrictions felt by $\mathrm{P} / \mathrm{Ts}$ regarding programme limitations of the LMDAs, these have been eliminated by the flexibility that is available in the programmes that can be offered through the Labour Market Agreements. Here, there is no prescribed list in the agreements, just an array of activities that can include: skills training; on-the-job training and workplace-based skills upgrading; group interventions and job readiness assistance; financial supports and benefits such as loans, grants and living allowances; employment counselling and services; and labour market connections such as services to facilitate matching supply and demand; and services that promote and enhance labour market efficiency. Under the LMAs, each jurisdiction has a multi-year plan that identifies their particular labour market goals and objectives. This is supplemented each year by an annual plan that identifies P/T priorities, eligible programmes and services and anticipated results. It also identifies how the available federal funding will be allocated between various $\mathrm{P} / \mathrm{T}$ programmes. $\mathrm{P} / \mathrm{Ts}$ do not provide this plan to federal officials, but directly to their citizens.

50. Although it may be argued that the LMDA restricts P/T flexibility to design policies that meet their particular needs, in reality when the LMAs are added to the mix provincial and territorial governments have considerable flexibility to develop and deliver those programmes that meet their particular needs, without federal constraints. This is clearly evident through an examination of the annual $\mathrm{P} / \mathrm{T}$ plans which are readily available on their respective websites or the federal website ${ }^{15}$.

\section{Client Eligibility}

51. Clearly, there are significant client eligibility restrictions on LMDA funded programmes. Since these are funded through the EI account, only those clients with active or recent (in the last 3 years or 5 years in the case of parental benefit clients) EI claims have access to Employment Benefits such as training, wage subsidies or self-employment supports, which are more expensive and generally involve longer-term interventions that can last from several weeks to a year or more. This meant that in the early days of the LMDAs, those most in need of labour market programming - for example, social assistance clients, immigrants, people with disabilities, Aboriginal persons, new entrants to the labour market - could only access short-term employment assistance services.

See http://employment.alberta.ca/documents/RRM/RRM-PUB_lma_annrpt_0910.pdf for the Alberta plan and www.gnb.ca/0105/AnnualPlan.pdf for the New Brunswick plan. Alberta's plan integrates the LMDA and LMA planning process. 
52. After the LMDAs were put in place, provinces/territories provided significant input to HRSDC that there was a big gap in programming that the LMDAs could not fill because of the restricted eligibility criteria that had been federally imposed. As a result, the Government of Canada agreed to provide additional funding for new programming to fill that gap. Not only did they make the Targeted Initiative for Older Workers available, they also offered LMAs which are broader in terms of who can be served.

53. The LMAs came about because of protracted lobbying on the part of P/Ts, as well as organisations representing clients who were not eligible for LMDA funded programmes. Federal staff were able to successfully present these views in order to secure the necessary federal funding allocations. Under the LMAs, a variety of client groups are eligible for services, including unemployed individuals (e.g. social assistance clients, immigrants, persons with disabilities, older workers, youth, Aboriginal persons, new entrants and re-entrants to the labour market) and employed individuals who are low skilled. Although there are significant restrictions under the LMDAs, the LMAs have provided each P/T government with a significant degree of flexibility in serving a wide variety of client groups, including an opportunity to enhance $\mathrm{P} / \mathrm{T}$ programmes already in place.

\section{Performance Measures and Targets}

54. The LMDA performance measures were developed through the F-P/T negotiation process. The early LMDAs (for example Alberta, New Brunswick) were negotiated primarily by federal representatives in each P/T, liaising with central officials in Ottawa. Given the financial concerns of the day, from a federal perspective the performance measures that were ultimately selected were those that ensured that EI caseloads would be brought down through quick returns to work and the saving of money to the EI account. As part of the delegation of authority to $\mathrm{P} / \mathrm{Ts}, \mathrm{P} / \mathrm{Ts}$ were required to share actual client data, and the Government of Canada committed to centralised reporting through the annual EI Monitoring and Assessment Reports.

55. With respect to targets under the LMDAs, HRSDC publishes actual and expected national targets for the three performance indicators before the beginning of each fiscal year. Each province/territory develops its own targets and this is then discussed with Service Canada officials resident in the P/T as part of the annual planning process and rolled up into national reports. Alberta and New Brunswick officials highlighted that they had consistently achieved or exceeded their LMDA targets.

56. There is a very different perspective with respect to the LMAs, where HRSDC officials do not view $\mathrm{P} / \mathrm{T}$ governments as being accountable to the Government of Canada but as being accountable to their own provincial or territorial citizens. Based on their experience with other programmes and the difficulties they encountered in securing P/T data, when the LMAs were developed federal officials decided on a very different approach: a) to impose more significant performance indicators and b) to trust the P/Ts to report on these indicators without requiring an exchange of data ${ }^{16}$. Targets under the LMAs are set by each government and publicly released in the annual plan.

\footnotetext{
${ }^{16}$ The ten performance indicators outlined in the LMAs were substantially developed by HRSDC and then reviewed at a major workshop where the accountability regime was presented and P/Ts had an opportunity to provide follow up comments before the agreements were finalised.
} 
57. In general, P/Ts are not compared with each other nor are benchmarks established that would allow for such a comparison to be made. Federal officials in particular highlighted that it is very difficult to undertake comparisons between provinces and territories, primarily because the programmes are so diverse from jurisdiction to jurisdiction. Now that all jurisdictions have LMDAs, HRSDC sees that they have a key role to play in sharing best practices, and they have convened workshops on this. To date these have only involved government officials, not the wider labour market community, including service delivery providers.

58. Both federal and P/T officials interviewed for this study felt that under both the LMDAs and LMAs there was sufficient flexibility at the P/T level in the F-P/T accountability regimes that were already in place. There is no evidence to date that this is a performance or target driven F-P/T relationship.

\section{Collaboration and Partnerships}

59. In terms of collaboration and partnerships, P/T governments have a high degree of flexibility. The closest the agreements come to this is a provision in the LMAs that prescribes that in developing their annual plans, provinces/territories will consult with stakeholders, including business and labour representatives, community organisations and representatives of the official language minority communities in the P/T and report publicly on this in their annual plan. While the agreements are not prescriptive on non-government collaboration, they are precise on how federal and P/T governments should collaborate with each other. It is, however, up to each P/T to decide whether they wish to enter into co-delivery arrangements, either with the Government of Canada, or with other P/T or municipal programmes as they deem appropriate.

\section{Budgets and Financing}

60. With the LMA funding made available in 2007, and the additional funding allocated through the Economic Action Plan in 2009, this review did not identify a problem with the adequacy of federal funding that has been allocated to $\mathrm{P} / \mathrm{T}$ governments for active labour market measures. The money comes in separate envelopes to each $\mathrm{P} / \mathrm{T}$ government, and it is up to them to make decisions as to how it is allocated to eligible programmes within the P/T. Because of the way that the funding envelopes are structured and how they must be individually accounted for, provinces/ territories are not free to move federal funds from the LMDAs to the LMAs, the TIOW or the LMAPD, thereby limiting their flexibility. In addition, other than through lobbying, P/Ts have no ability to influence the size of each of the funding envelopes.

61. Budgets and financing seem to be the area where P/T governments have the least amount of flexibility with respect to their accountability relationship with the Government of Canada. Both federal and P/T officials acknowledge that improvements could be made to how the Government of Canada allocates money to $\mathrm{P} / \mathrm{Ts}$ for different labour market purposes and client groups, and that some sort of consolidation of the funding streams should be explored.

\section{Staffing and Outsourcing}

62. Aside from restrictions in terms of how federal employees can become provincial employees in the LMDAs, there is nothing in either the LMDAs or the LMAs that restricts provincial and territorial governments in their ability to hire, recruit, train and pay personnel and assign them to tasks at their 
discretion. P/T governments are also free to contract out the services provided under the agreements to external providers, as they see fit. In effect, provincial/territorial governments do things differently; as will be seen later, Alberta contracts extensively to for-profit service delivery providers, while New Brunswick focuses primarily on the not-for-profit sector. Other than how transferred federal employees are treated through the LMDAs, P/T governments have complete flexibility to decide how the services to be offered under the agreements will be delivered.

\section{In summary}

63. On balance, it can be concluded that provincial and territorial governments have a considerable degree of flexibility in the actual management of federal labour market programmes under the accountability frameworks in place. On the other hand, the strategic vision, programme design and programme parameters for the federally-funded active labour market measures are mostly decided by the Government of Canada, with some degree of input from senior P/T officials. Given the additional funding that has been made available over the past few years, this has allowed P/T governments to design and deliver programmes of their choosing for those target groups they perceive to be most in need. To date, the performance measures, targets and reporting requirements in the LMDAs and LMAs have not proven to be a significant impediment to flexibility, nor have the increased requirements in the LMAs with respect to collaboration and partnership. P/Ts were already doing this, so this is just a reporting requirement. Other than restrictions with respect to federal jobs transferred to P/T governments in conjunction with the initial LMDAs, P/Ts are fully free to decide the degree to which they will provide services directly through $\mathrm{P} / \mathrm{T}$ staff vs. outsourcing. The key restriction on $\mathrm{P} / \mathrm{T}$ flexibility comes from how the federal money is provided: that is, through defined funding envelopes with a requirement that $\mathrm{P} / \mathrm{Ts}$ account for each envelope separately without an ability to transfer funds from one envelope to another. There is also no defined F-P/T process for P/Ts to influence the size of the funding envelopes, and the opportunity through the bilateral LMDAs to discuss the formula or how these funds are distributed between provincial and territorial jurisdictions has not been used. As a result, these elements of labour market policy in Canada are still firmly under federal control. In terms of accountability, while an examination of the agreements demonstrates that the legal, fiscal and performance accountability provisions of the F-P/T agreements are strong, reporting requirements are less robust. 


\section{FLEXIBILITY AT THE LOCAL LEVEL: THE ALBERTA CASE STUDY}

64. We turn now in this study from an examination of the broader F-P/T relationship - that would apply to any bilateral arrangement - to examine what two individual provinces are doing with the previous federal responsibilities that they have assumed post-devolution. A key question examined in this study is whether responsibility has been retained at the provincial level, or whether it has moved down to allow for flexible decision making at the sub-regional and local level. To answer this question the detailed interview questions, e-survey and roundtables that were carried out in Alberta and New Brunswick in 2009 and 2010 are drawn upon.

\section{The Alberta Context}

65. With a population of 3.7 million in 2009, Alberta is the most populous and fastest growing of Canada's three prairie provinces. It became a province on September 1, 1905. Today approximately $81 \%$ of the population live in urban areas, especially the Calgary-Edmonton corridor, one of the most densely populated urban areas of Canada. Due to vast oil reserves, Alberta's economy is one of the strongest in Canada, supported by the petroleum industry and to a lesser extent, agriculture and technology. Alberta is considered as a "have" province - that is, it receives no equalisation payments ${ }^{17}$ from the Government of Canada and the citizens of Alberta are considered as net contributors to Canadian federalism. The provincial per capita GDP in 2007 was by far the highest of any province in Canada at $\$ 54075$, almost twice that of New Brunswick at \$29 900 (Statistics Canada, 2008). Alberta has one of the lowest unemployment $(6.6 \%)$ and highest employment (68.5\%) rates in Canada (Statistics Canada, 2010). Over the past decade key labour market challenges are skills and labour shortages, with Alberta initiatives focused on improving the skills of resident Albertans and increasing inter-provincial and international migration. Not all areas of Alberta are experiencing the same degree of prosperity. The OECD study tour held roundtables in Edmonton (an area of relative prosperity) as well as the rural community of Wetaskawin. Here the presence of a large on-reserve Aboriginal population makes labour market programming extremely challenging. With the economic downturn starting in the fall of 2008, the growth in the Alberta economy has moderated and unemployment has increased.

66. Alberta was the first province to enter into a Labour Market Development Agreement (LMDA) with the Government of Canada in December 1996. Before devolution, Alberta had started to build civil service expertise and capacity in the labour market policy domain and was viewed in particular as a leader capacity"- their ability to generate tax revenues. 
in labour market information. The provincial government also offered career development services to all citizens, employment services to social assistance recipients, and second-chance training programmes to those considered as disadvantaged in the labour market. There was a pre-existing long-standing federalprovincial Labour Market Agreement for Persons with Disabilities (LMAPD). Assuming responsibility for federally delivered labour market programmes and services provided the Government of Alberta with additional skilled staff, capacity, opportunity and motivation to develop a seamless, integrated workforce development service available to all Alberta citizens. As of 2010, Alberta Employment and Immigration (AEI) is the provincial department with the designated responsibility for active labour market programming. AEI's 2008/09 annual report identified \$193.5 million in transfers from the Government of Canada related to labour market programming ${ }^{18}$. When extrapolated to the 2009-10 budget estimate and compared to departmental costs for non-income support employment programming, this federal contribution represents approximately $50 \%$ of Alberta's total AEI active labour market expenditures ${ }^{19}$.

67. AEI's labour market programmes and services are operated under the authority of the Deputy Minister of Employment and Immigration (AEI), supported by the Assistant Deputy Minister of Workforce Supports, the Assistant Deputy Minister of Delivery Services, and six regional directors. With approximately 1500 staff in 16 Job Corps and 59 delivery sites across the province, AEI Labour Market Information Centres (LMICs) and Career Services Centres bring together supports for individual Albertans - to help them prepare for, train for, find and keep a job - with supports for employers and industry to help them attract, find, retain and develop a skilled Alberta workforce. AEI provides within one organisation a broad spectrum of activities related to employment and the workplace (for example social assistance to help low income Albertans cover their basic needs, labour relations, workplace health \& safety, employment standards, and immigration policy \& programming).

68. In general, AEI staff provide the following active labour market services directly: labour market information and resources; access to on-line job search and career planning resources; assessment and referral, and industry liaison. Career and employment counselling, training assessment, resume writing, training, placement services, work experience programmes, self employment assistance, and access to more intensive interventions and supports for those with barriers to employment use a mixed delivery model, but more often employ service providers (for-profit, not-for profit as well as post-secondary institutions). Although AEI services are available to all Albertans, they are most heavily utilised by federal Employment Insurance and provincial social assistance recipients.

\section{Accountability Provisions of the Provincial-Regional-Local Relationship}

69. All labour market programmes and services provided by AEI are governed by provincial legislation, regulation or policy. This ensures that the necessary legal and fiscal accountability provisions are in place. However, departmental activities are primarily motivated by and organised around the

This includes LMAPD. Federal payments to Alberta under the LMDA, LMA and federal stimulus agreements for $2009 / 10$ are estimated at $\$ 207.7 \mathrm{~m}$.

Author's calculation- see page 69-72 of 2008/09 Annual report for breakdown of federal funding (available

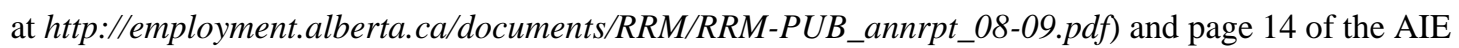
2009 Business Plan (available at www.finance.alberta.ca/publications/budget/budget2009/employment.pdf) 
Employment \& Immigration Business Plan prepared each spring for a three year period. The business plan outlines the vision, mission, strategic priorities, core businesses, goals, performance measures and targets for all Ministry programmes, including those that are the subject of this OECD study. This departmental business plan is informed by the Government of Alberta Strategic Business Plan and is often supplemented by a mandate letter from the Premier to the Minister on specific priorities for his/her department.

\section{Box 2. Employment and Immigration Business Plan 2009}

Goal one Alberta is able to meet its labour force requirements.

Goal two Alberta is able to attract and retain workers to the province.

Goal three All Albertans share in and contribute to the economic prosperity of Alberta.

Goal four Alberta has a fair, safe and healthy work environment.

Goal five Alberta's labour relation laws are administered in a fair and equitable manner.

Goal six Alberta has an effective mechanism for the final appeal of Worker's Compensation Board decisions.

70. The employment strategies outlined in the departmental business plan are executed at the regional and local level by AEI regional directors and area managers supervised by the ADM of Delivery Services. Delivery Services Division develops an operational plan that covers the entire province, and each of the six regions as well as their local offices develops a corresponding operational plan covering their respective geographic area. They also develop a complementary skills investment plan that sets out contracting plans and priorities for the year. All regional and local activities are identified against the applicable core business, goal and strategy in the provincial plan through a logical, systematic process using a standard template that moves the departmental plan down into each division, from the division to the region, from the region to the local office, and from the local office into each manager's and employee's personal performance plan. The business planning process also includes results reporting at all levels on a quarterly basis that is ultimately rolled up into the AEI annual report which is publicly released each fall. This defined planning and reporting process significantly structures relationships between the Assistant Deputy Ministers of Workforce Supports and Delivery Services, as well as between each ADM and their respective staff, ensuring a continuous feedback loop.

71. The accountability and financial management framework (AFMF) applies to all Skills Investment programs and services, encompassing tuition-based, and contract-based training. The majority of tuition-based providers hold an Accountability Framework Agreement (AFA), which is a contractual arrangement for the delegation of authority from Alberta Employment and Immigration (AEI) to training providers that sets expectations related to specific responsibilities and requirements involving assessment and service management. Contract-based providers (usually private and not-for-profit agencies) are governed by a contracting policy manual and individual contracts utilize a standard template; in addition 
all contracts are let through a standard public request for proposal (RFP) process, ensuring openness and transparency.

\section{Degree of Flexibility Alberta Regional and Local Offices have to Manage Programmes}

\section{Strategic Approach, Programme Goals and Programme Design}

72. Province-wide AEI strategic labour market directions are outlined in the Skills Investment Policy Framework (2003), Building and Educating Tomorrow's Workforce (BETW) - Alberta's Ten Year Strategy (2006), and Supporting Immigrants and Immigration to Alberta (2005). These were all developed through a broad consultation process with business, labour and interested stakeholders, substantially increasing Alberta's democratic accountability within the sector. AEI facilitates five industry contributor groups involving industry sectors and government actors that support the strategies under BETW including standing committees (an ADM Coordinating Committee and Labour Force Planning Committee). They have also formalised processes to engage with colleges and contracted training providers (the Training Provider Advisory Committee), community agencies (the Strategic Alliance) and Aboriginal Human Resource Development Agreement holders (the Aboriginal Best Practice Table).

73. In the past three years, Alberta has invested heavily in province-wide sector specific workforce development strategies in logistics, forestry, not-for profit, construction, manufacturing, energy, tourism \& hospitality and retail. The healthcare sector strategy is under development. These sector strategies ensure industry $^{20}$ ownership of their particular workforce development goals and challenges within the Alberta context and that industry (not government) leads in implementing the priority actions that have been collectively agreed to.

74. As identified above, AEI has a very structured, top-down process for determining provincial labour market programme goals and programme design. This is embedded in the political structure of the province, starting with the Premier's letter to each of his Ministers, through to each Government of Alberta department. This business planning process has been refined over the years such that it is an integral part of every employee's job, including how individual performance is assessed. Part of the reason the process is so embedded is due to the involvement of long-serving departmental employees, with considerable labour market knowledge and expertise. The annual planning process is constantly reviewed, monitored and improved based on feedback from across the department, including those at the local level.

75. AEI is organised in such a way that the policy function is clearly separated from the delivery function, and all staff are acclimatised to this separation. As noted by the ADM of Delivery Services: "It is my job to meet the performance measures and deliver the programmes, and the ADM of Policy's job is to design the programme and decide on the most appropriate measures". The strategic direction provided by Building and Educating Tomorrow's Workforce was welcomed by AEI delivery staff as it provided them with permission to move beyond working with just unemployed Albertans to also making connections with Alberta employers, a role that was previously viewed as the responsibility of the provincial economic development department. This new direction was realised through the development of a new staff position

This includes business and labour councils, associations as well as individual employers. 
called Business and Industry Liaison Officer (BIL) which is now in place in every region across the province.

\section{Box 3. Business and Industry Liaison Officer}

The Business and Industry Liaison will focus on matters related to workforce partnership development as it relates to Building and Educating Tomorrow's Workforce (BETW): to inform, attract, develop and retain, i.e. workforce development, labour force development, economic labour market information, networking, collaborating with a variety of stakeholders, and providing strategic thinking. This position will liaise with business and industry sectors to gather information and understanding related to: attracting, developing, informing and retaining that enable AEI to collaborate on, develop and support appropriate responses. The duties of this position are integral to the overall development of strategies within the area to expand AEl's role in working with business and industry. The incumbent will establish communication links with local staff, service providers, area colleagues and regions within AEI, cross-government and inter-provincial government, to foster innovation and development with both internal and external stakeholders. Keeping abreast of the most current business, industry and employer workforce development issues and challenges is critical in this role.

76. Despite the fact that policy is clearly determined at a provincial, as opposed to a regional or local level, $82 \%$ of those surveyed confirmed that AEI regional and local staff have ample opportunity to be directly involved in the policy development process, and that this involvement can influence programme design. There is regular and ongoing delivery staff involvement in both internal to AEI policy development processes (through the Programme and Services Alignment Team), as well as those that involve larger consultations with industry. This is both formal and ad hoc. The department is small enough (less than 1500 staff with regional staff distributed into six regions) to allow for short lines of command and intensive communications both within the Delivery Services division as well as across to the Workforce Supports policy division. Regional directors seemed very comfortable that, once a programme design has been set, that this is the programme that they will deliver, with the understanding that there are internal processes that allow for review and change. According to one respondent, "AEI staff have a culture of working within the rules, or making the rules work for them". If issues remain, delivery staff work to get the policy changed, recognising that sometimes this can be a long process. This makes for a very positive organisational culture.

77. One of the questions asked in the interviews and e-survey was how things had changed with devolution through the LMDAs. One respondent noted that "Ottawa suddenly got a whole lot closer, and proximity breeds trust". Others noted that in the pre-LMDA days, federal officials in the Alberta region of HRSDC had limited opportunity to influence national policy development, and programmes designed in Ottawa would just land on their desks for delivery. In their view with the province now responsible, policy development is a more collegial and iterative process as policy and delivery staff meet on a regular basis. It is also better connected to Alberta political priorities, with Alberta politicians much more accessible than federal politicians used to be. The LMDAs and LMAs allow the province to adjust programmes to respond to local economic development needs. Since programme design is under provincial control, there is a quicker response, as well as a larger array of programmes and services than was previously available. It was noted in particular that Alberta focuses more on outcomes than process in contracting and that the province runs a more open and transparent process. In the view of those interviewed and those who 
completed the e-survey, this produces better outcomes, makes the department more accountable to Albertans, and is an improvement over federal delivery.

78. An area where delivery staff feel that they have considerable flexibility is in terms of deciding on the mix of programmes, choosing from a "tool box" of programmes that are available. Being able to choose from a mix of programmes allows them the flexibility to tailor their labour market interventions to their local labour markets and client demographics. There did not seem to be a need for local employment strategies to be designed, as the ones available could be adequately adapted to their needs. By the connections that AEI delivery staff now have with industry through the new Business and Liaison officer positions, regional directors feel that they are well-positioned to reflect industry needs in AEI programs. On the other hand, 50\% of local managers who responded to the e-survey felt that there were labour market priorities that they could not address through AEI programming. This related primarily to providing supports to youth with limited skills and job history, as well as persons with disabilities and immigrants.

79. Service providers also seemed to recognise and accept that, while programme parameters are set at the centre, this still allowed them the flexibility to achieve the goals expected from their respective Boards of Directors. Each developed their own priorities, and then worked with AEI to see if they could get those priorities funded given the alignment between their goals and those of AEI. These views were not shared by all service providers interviewed; for example a respondent involved with a programme to support women in trades felt that inflexibility in AEI programme design sometimes forced them to offer unnecessary programming.

\section{Client Eligibility}

80. AEI staff view two groups as departmental clients: 1) the unemployed and other Albertans in need, and 2) Alberta employers and industry. There are no central office restrictions on employers or industries served, and AEI service delivery staff are fully free to focus on those occupations and industries that are most relevant in their local areas. However, they are also expected to support as needed the provincial sector strategies for those sectors that have been identified as provincial priorities: logistics, forestry, not-for profit, construction, manufacturing, energy, tourism \& hospitality, retail, healthcare and education.

81. In terms of individuals, AEI regional and local offices are expected to work with all Albertans wishing to access their services, and all citizens and employers are encouraged to use the front end services of the LMICs and Career Services Centres. Where restrictions around client eligibility becomes more significant is in terms of individual access to the more intensive training and employment services, many of which are mounted with specific client groups in mind. This is a function of provincial regulations regarding learner support. The difficulty that had emerged was that many of the more intensive programmes were only available to clients in receipt of federal EI or provincial social assistance. This left many Albertans ineligible for services as there was only limited provincial funding available. These restrictions around client eligibility have been substantially eased with the additional federal funding made available through the LMAs and the Economic Action Plan. However, over $80 \%$ of staff who responded to the e-survey identified that there were still vulnerable groups that they could not help to the extent that they would like. This included the Aboriginal community, refugee claimants, homeless, those with mental 
health problems, and those deemed ineligible due to marginally excess income. This may, however, be more an issue of mandate and availability of resources, as opposed to being the result of policy design.

82. This lack of flexibility in terms of client eligibility was particularly noted by Alberta service providers, some of whom had not yet seen the programme changes made possible through the new federal LMA funding. They thought that restricting eligibility to only EI clients was inappropriate, and that eligibility for programmes should be citizen based. In their view, as a result of eligibility restrictions, many people cannot access the training programmes they need. One service provider noted that there are many women and Aboriginal people that cannot take part in programmes that would benefit them, and the service provider has had to fundraise to make a space available. In her view, people employed in lowpaying work should be eligible to take advantage of government assistance for training programmes. The restrictions on serving refugee claimants was also identified as a problem, as these people are coming for service yet cannot be helped.

83. On the other hand, it was also noted that AEI does have a "counsel to leave employment" policy whereby AEI staff can not only approve training for those working in low-wage jobs, but also approve a quit such that the individual becomes eligible for EI benefits. It was also noted that AEI had recently changed departmental policy in terms of clients that could be served, including services provided to Aboriginal Albertans living on reserve. Previously, the Government of Alberta position was that these services should be provided by the Government of Canada due to their constitutional responsibility for Aboriginals and land reserved to Aboriginals. Although only 6\% of Albertans are of Aboriginal descent, they are significantly disadvantaged in the labour market, especially those who live on reserves where there are very few employment opportunities. With this change in policy to permit the provision of provincial services on reserve, AEI local and regional offices now have the flexibility, within the funding they are allocated, to decide the degree to which customised Aboriginal services are provided in their area. This has produced interesting collaborative projects in some areas (see Box 4 below). In tackling the multiple barriers faced by some Aboriginal people, regional and local AEI officials also require flexible policies from other provincial departments (in the field of housing, transport) to significantly change employment outcomes. According to the fieldwork for this project, this flexibility was not always forthcoming.

\section{Box 4. AEI Services to Aboriginal People on Reserve in Central Region}

AEI provides basic Career and Employment Information Services to all Albertans through internally operated Labour Market Information Centres (LMIC) and contracted Labour Market Resource Centres. Services are also provided specifically to Aboriginal Albertans through Aboriginal Employment Centres. In Central Region an Aboriginal Employment Service is in operation in Red Deer, another operates on reserve at Hobbema, and plans are underway to provide similar services in the Rocky Mountain House area. Upon occasion the mobile Career Cruiser has been made available at Aboriginal schools on reserve. In Central Region Aboriginals who are or have been living on reserve but are interested in employment in off-reserve urban cities or towns have access to a training programme that provides basic employability skills. Occupational training is funded by AEI and provided in partnership with First Nation Human Resource Departments. 
84. In some regions it is not services to Aboriginal persons that are a key need. The proportion of Albertans who are visible minorities is $14 \%$. In Calgary in particular, many of the initiatives made possible through the new funding are targeted to recent immigrants. It is up to each Regional Director and local office to determine which target groups should receive priority programming. This is not determined by central office staff.

\section{Performance Measures and Targets}

85. The Government of Alberta prescribes an approach to performance measurement for all provincial departments. This overall Government of Alberta perspective plus the performance measures and targets in the federal-provincial LMDA and LMA provide the starting framework for the performance measurement system used by AEI.

86. Historically, AEI had a single benchmark, set at $70 \%$ or more of learners reporting that they were employed or in further training when surveyed in the months following training. This was further refined in 2005/06 through the Skills Outcome and Indicators project, which identified 15 indicators and five overall outcomes (derived from the indicators) that demonstrated how well AEI clients were doing and whether the time spent in AEI programs made a difference. This information was rolled out to AEI service providers in 2007. The data necessary for managing the system is gathered through various sources including Mobius $^{21}$ (a new client service integration system) as well as the Work Outcomes Reporting Project (an ongoing monthly suite of telephone surveys that collect follow-up data on former clients).

87. Like programme design, most performance measures and targets used by AEI are provincially set and outlined directly in the Business Plan. In the words of one local manager, "although we can set some targets, most are laid on by regional office". There was no reference in the interviews or staff e-survey undertaken for this project, nor a review of Alberta documentation, to how and whether federally required performance measures shape the Alberta measures or indicators. Alberta views itself as a "leader" when it comes to performance measurement in Canada, and the enhanced measures and targets in the LMA over the LMDA were positively received. Work is underway in AEI on benchmarking for various programme elements. AEI also undertakes evaluations of their various programmes according to a plan that is developed and reviewed annually. Although Alberta reports their programmes results publicly through annual reports, evaluations are undertaken for internal purposes and are not made available other than to selected stakeholders as deemed appropriate.

88. In terms of process, AEI performance measures are debated and set at a provincial level (with delivery services input), and it was noted that they don't change much from year to year. There is a crossdivisional group that develops the indicators and targets for the entire department. Locally determined measures and targets can also be set, especially for high risk groups. It is noteworthy that the only place where hard targets are identified is in the provincial business plan; however, these are not formally translated down to the regional and local level business plans. 
89. Hard targets do however appear in the Accountability Framework Agreements (AFAs) with postsecondary institutions and service contracts with third party providers. Staff interviewed all felt that consistent measures are important. As outcome measures, they felt that these do not constrain delivery to the same degree they would if they were output measures. Since delivery services is responsible for the contracting process, in their view consistent measures and targets are required in order to hold their service providers to account.

90. For AEI regional and local offices, there are no sanctions for failing to meet targets, other than that offices might get written up by the Auditor General. This does not appear to have happened. At the time of this research AEI local offices were not being benchmarked one against another, in fact the ADM of Delivery Services suggested that he was not looking for consistency but was looking for innovation. Inconsistency is encouraged so that innovation can be fostered. However, AEI central office staff noted that they would be interested in doing more detailed comparisons between offices, but that there were system limitations. In addition, in their view the local offices are so different that it may not be appropriate to compare one with another.

91. If service providers do not meet their targets, the sanction is that their contract may not be renewed. There is a very competitive and open bidding process for securing AEI contracts. Having targets and measures in the contracts was accepted as the way that business is done in Alberta. Service delivery contractors noted some ability to negotiate the targets as part of the contracting process. In addition, some service providers developed their own targets that provide higher standards than the provincial targets. All seemed quite comfortable with the notion of targets and measures, and that these would be used to assess performance. One service provider commented that it was not appropriate for the government to consider them as a contractor, that they were really an extension of government and doing work that was under the responsibility of government. He was particularly concerned that accountability seemed to be mostly a one-way process, that government was not willing to accept accountability for the agencies and could leave them high and dry in terms of staff obligations if they decided to cancel funding.

\section{Collaboration and Partnerships}

92. Almost $90 \%$ of AEI staff surveyed identified that they work with other agencies to develop local strategies that meet local needs, and over $80 \%$ felt that they were able to contribute fully or to a great extent to the delivery of these strategies. It is noteworthy that partnerships at the local and regional level are for operational - not strategic - planning purposes, as this takes place at central office. There were extensive examples of collaboration and partnership identified, including with industry sectors (both national and within Alberta), Regional Economic Development Agencies, Chambers of Commerce, ASETS holders, school divisions, training providers, post-secondary institutions, community organisations, and other levels of government. The change of policy regarding supporting Aboriginal training on reserve has resulted in new partnerships with ASETS holders and Indian and Northern Affairs Canada ${ }^{22}$. An enhanced interest in increasing immigration to deal with workforce shortages has resulted in increased linkages with HRSDC, Citizenship and Immigration Canada, and immigrant serving associations in Alberta.

\footnotetext{
${ }^{22}$ The name of this Department has recently changed to Aboriginal Affairs and Northern Development Canada
} 
93. The new Business \& Industry liaison positions have helped AEI to reach out in particular to industry and individual employers, and examples were given of workshops on employee attraction and retention, workplace bullying, work-life balance, diversity awareness, succession planning etc. An employer at one of the round tables noted that AEI was one of the most open and responsive Alberta government departments that he worked with. AEI staff noted that they had played a catalyst role in the development of a required day care service and facilitated the development of new transportation facilities for rural communities. Having the capacity that this intermediary role provides has allowed AEI staff to facilitate cross-sector policy responses to urgent local problems that are outside AEI's mandate.

94. AEI partnerships are primarily determined at the regional and local level as needed to achieve departmental goals. Sometimes central office officials will suggest the development of new partnerships for example, the development of social indicators came from Cabinet direction. Some partnerships involve joint funding of an initiative, for example around Aboriginal partnerships. AEI is a valued partner as they have funding available for programming. Partnership working is formally recognised in the AEI performance appraisal system through the use of a common template. Collaborative behaviour is highly recognised - for example, the ADM of Delivery Services provides comments and emails and considers that $90 \%$ of his discussion with his managers in relation to performance focuses on how the individual is managing partnerships in order to achieve departmental goals.

95. Alberta's economic development network consists of 13 Regional Economic Development Alliances (REDAs) throughout the province. These are funded by the Government of Alberta, and do not have a federal funding presence. According to the provincial website, REDAs are a collaborative approach by communities and supportive partners to achieve prosperity in a defined geographical area based on a shared economic vision for the future. There is no specific mention of a mandate for workforce development. The alliances are meant to enable regions to compete more effectively in a global marketplace and improve investment attraction, resulting in greater prosperity locally, regionally, and provincially. All AEI regional directors and their staff relate to one or more REDAs in their particular region or area, and often facilitate the necessary input with respect to any workforce development needs. However, $82 \%$ of those who completed the AEI staff survey noted that local boards and committees (including REDAs) do not plan the strategic direction of their work, and only 33\% would welcome this direction. This may be a result of the fact that AEI has the capacity within such a broad organisational structure to respond to many economic development issues on their own, without needing to co-ordinate their work with the REDAs. While positive, this lack of connection in itself may constitute a policy silo with respect to other relevant policy domains.

96. Service providers also have extensive collaborative relationships, especially with industry, Regional Economic Development Agencies, and governments who are their funders. Although government may suggest who they collaborate with, they find the most success when they are able to identify collaborators and partnerships appropriate to their needs. These partnerships are vital in informing the nature of the service they provide.

97. AEI staff are often co-located with other provincial government departments; this varies and is not prescribed by central office, as it is considered an operational issue. At the beginning of the implementation of the LMDA, Canada and Alberta were co-located through Canada-Alberta Service Centres, and fifteen sites still remain. However, they are becoming less and less common as leases are 
renewed and each requires more space. There is no consistent provincial model and no mandate from the centre to deliver in a specific way - it is driven by infrastructure needs and local desires. AEI and HRSDC offices have been drifting apart as there is less and less of a business need to co-locate. EI claimants now get most of their services from the federal government by phone and email, so have no need to come into an office where AEI resources are available. In addition, the Government of Canada's decision to establish Service Canada brought HRSDC services together with many other federal services, distancing them from pre-LMDA efforts to run a seamless Canada-Alberta labour market service. Service providers are sometimes involved in co-delivery arrangements, for example with community colleges and other community organisations.

\section{Budgets and Financing}

98. Each AEI region is assigned its own budget by central office, with programmes designated by sub-codes and money assigned to defined envelopes (for example, manpower, income support, skills investment etc.). It was noted that departmental financial policy makes it difficult to move manpower funding into programme dollars. Although AEI regions (not local offices) control most of the money and supervise the letting of contracts, one survey respondent noted, that "we can usually get either approval or forgiveness for what we do". There is no funding held back for special local initiatives, all is allocated through the budget process. However, if new circumstances emerge, there is always the possibility of adjusting services, as long is money is available. In terms of the adequacy of budgets available to regional and local offices, neither the interviews nor the e-survey turned up compelling evidence that funding was insufficient, although it was noted that some staff were overloaded.

99. With the economic downturn, AEI staff have found that they often do not have the right balance of programmes, especially since they are now seeing people who are more highly employable. Staff noted many more young people coming into their offices, many of whom did not finish their basic education and have low skills. As the competition for jobs increase, people with lower skills can find it harder to succeed in the labour market. AEI delivery staff find that the easiest way to deal with new and emerging needs is though the expansion of existing outsourced contracts. This is much easier than letting a new contract which, under AEI contracting rules, is a time consuming and complex process.

100. From the regional directors' perspective, the money is relatively fluid and can be moved around within an office and within a region. They noted that regional delivery staff do not manage budgets line by line; instead they manage to the bottom line, and can use a surplus in one envelope to cover a deficit in another. The ADM of Delivery Services also noted that there is flexibility to move money between regions, for example if one has a surplus and another a deficit.

101. On the other hand, the e-survey noted budgets as the area of lowest flexibility for local office managers, who identified a need for greater flexibility here. Eleven managers ranked flexibility in budget management as only moderate, five said it was low, and only one said it was high. Over half of the respondents thought that the level of paperwork that they must deal with was high. Funding complexity vis-à-vis both learners and programmes was identified as a problem.

102. Both central office and regional AEI staff identified a significant problem in administering the LMDA and the LMA and the funding increases through the 2009 Economic Action Plan. What has emerged is a number of funding envelopes (both federal and provincial) that each must be tracked and 
accounted for separately. As delivery administrators, AEI regional directors cannot control who is using their service, they can only try to manage the funding allocations for the different client groups behind the scenes. AEI central office staff are working with their delivery offices on how to manage and where to allocate the money, and the budget implications. There is some flexibility to move dollars between envelopes, but there are also difficulties and considerable complexity. This has been exacerbated by federal decisions to identify a new category of EI client - long tenured workers. Although in this case Alberta is not providing funding for this training (the EI client is a fee-payer), they have to approve the programme and failure to do this in a timely fashion impacts an individual's EI benefit cheque.

103. Provincial officials noted that they were going to let this complexity play out and try to figure out over the fullness of time how things should be coded to one funding source or another. Although it is more work and creates challenges, Alberta officials were comfortable with the expectations of the new federal dollars. In their view, both governments are on the same page and desiring the same outcome - that is, getting people employed and back to work.

\section{Staffing and Outsourcing}

104. AEI delivery staff are allocated to each region, and generally are not reallocated between regions. This allocation is adequate to meet the results identified in the departmental business plan. Regional directors are free to adjust staff allocations between different departmental activities and between local offices within their individual region, subject to the overall Government of Alberta classification system.

105. With the economic downturn, AEI has seen more people coming into their offices, more needing social assistance, and more being placed into training. They have seen a $132 \%$ increase in income support clients that are ready, willing, and available for work. LMICs are seeing a huge volume increase, and waiting lists for services have grown. As a result of these new demands, AEI has changed their services by implementing a new intake process, with specialised staff doing triage services and taking applications over the telephone. They have also changed their staffing model from caseloads to functions. For example, in income support, there used to be a provincial caseload model, but many offices have moved away from this to a unit model. Each regional and local office has the flexibility to decide how to allocate staff - the key issue is meeting the performance measures and targets assigned. Allocation of staff is an iterative process; delivery has to be able to shift to where the demands are. Although social assistance caseloads have increased with the downturn, the main central office direction to the regions is to ensure that they maintain a focus on career development and that resources do not get pulled into managing social assistance caseload volumes.

106. In terms of contracted services, AEI uses outsourcing extensively. In Edmonton and Calgary, this is managed at a regional level, in the other regions it is a mix of regional and local office contract management. Each region has a contract manager handling the regional contracting arrangements, the conditions of which, as previously noted, are highly prescribed by policy and highly controlled at the regional (not local) level. AEI has highly delegated financial authorities as regional directors can sign for up to $\$ 250000$, depending upon whether the contract is sole source or in response to a Request for Proposal (RFP). Regions can decide what they want to outsource (with the exception of union jobs), when, and to whom, as long as they follow the overall guidelines. It was noted that these guidelines can be quite restrictive when there is an immediate need to fast track - for example, it sometimes takes six to nine 
months to let a contract. Provincial waivers to the standard RFP process to allow sole sourcing are possible, but are usually only used in unique circumstances (e.g. for local Aboriginal organisations).

\section{Analysis of the Balance between Flexibility and Accountability with Respect to the Provincial- Regional-Local Relationship in Alberta}

107. Over the past decade, Alberta has had to cope with both significant skills and labour shortages as well as increased unemployment due to the economic downturn. Delivery staff have been forced to adjust programming developed in a different economic context to today's demands. In terms of the degree to which there is adequate flexibility on a provincial-regional-local basis within Alberta, there are some differences of opinion on the degree to which local and regional offices have the flexibility they would like to have around labour market programmes.

108. All AEI regional directors and ADMs interviewed for this research believe that regional and local offices have a high degree of flexibility to respond to their needs and issues, especially with respect to budgets and financing, collaboration and partnerships, and staffing and outsourcing. There is not a standard organisational model, and work processes are such that they do not prescribe how the interaction between AEI staff and the client is structured. This positive view was tempered by the e-survey results where, based on 17 responses, five local office managers thought that they had a high degree of flexibility, eleven thought it was moderate, and one thought there was a low degree of flexibility. All but one local manager agreed (six strongly) that more flexibility would enable them to deliver AEI programming more relevant to their locality. The area where local office managers would like more flexibility is in relation to budget management and client eligibility. It was noted a number of times that it would be administratively more effective to have a single federal funding source rather than separate envelopes though the LMDA, LMA, TIOW, and LMAPD.

109. All regional and local office staff acknowledge that they have limited flexibility in terms of overall strategic goals, programme design and client eligibility. On the other hand, they also believe they have ample opportunity to influence these factors which control their work through established processes within the AEI organisational structure. They did not perceive a need for strategic longer-term approaches to be developed at the regional and local level with their partners - in their view these connections are for "operational", not "strategic" planning. Rather than performance monitoring and control at the regional level being based on hard targets, management relies instead on the intensive top-down planning process, rolled-up operational planning, strong personal interaction, and the motivation and professionalism of staff to achieve the desired results. There is direct and intensive communication between the ADM for Delivery Services and the six regional directors, and they in turn with their local offices. It was noted that although AEI may seem like a policy driven, top down organisation, regional directors view it as a vision driven organisation, where regional and local staff have the opportunity to provide input into the vision. They are told, "here is the vision; it's up to you and your staff to figure out how to make it work". With this approach, there is considerable job satisfaction.

110. Maintaining accountability is a high priority for AEI, especially the legal, financial and administrative dimensions. This accountability is framed within a departmental context, and does not seem to strongly extend to horizontal accountability with provincial partners such as regionally based networks of post-secondary institutions and economic development agencies. Democratic and political 
accountability receives less AEI attention, although public reports are produced regularly and stakeholders are involved in programme design and development. Programme evaluations are not publicly available, limiting information and opportunities for engagement with interested labour market stakeholders, service delivery contractors, and interested Alberta citizens that might improve provincial programming.

111. AEI at a provincial level has a strong political and management capacity for designing and directing the variety of labour market programmes and services on offer in Alberta, and a strong sense of provincial ownership. The interviews and e-survey turned up few concerns with accountability at any level - provincial, regional or local - and little reflection (other than on the LMDA and LMA funding envelopes) that Alberta was accountable to the Government of Canada. While AEI officials were clear to point out that their accountability is to Albertans, they also provided the Government of Canada with the agreed upon 2008/09 LMA report in the timeframe and format requested. There was no sense of accountability to other provincial governments, citizens in other Canadian provinces, or Alberta service providers. Accountability to the Government of Canada is presented and understood as a "partnership" for example, there is an approved style guide for recognition that uses the words: "The Province of Alberta is working in partnership with the Government of Canada to provide employment support programmes and services". This may reflect the presence of significant provincial dollars in the basket of programmes and services on offer, long-standing Alberta expertise and capacity in the policy sector overall, as well as acknowledgement at the political level in Alberta of the importance of the sector as a key contributor to Alberta competitiveness and prosperity. 


\section{FLEXIBILITY AT THE LOCAL LEVEL: THE NEW BRUNSWICK CASE STUDY}

\section{The New Brunswick Context}

112. With a population of almost 750000 (in 2009), New Brunswick is Canada's third smallest province. The province is unique in a Canadian context as the only jurisdiction that is officially bilingual. Compared to other Canadian provinces, New Brunswick is relatively compact, with the three main cities Moncton, Saint John and Fredericton - relatively accessible to all residents by road. New Brunswick's urban areas have modern, service-based economies dominated by the health care, education, retail, finance, and insurance sectors. The rural areas of the province are known for forestry, fishing, mining and mixed agriculture. New Brunswick has historically been considered as one of Canada's "have-not" provinces, with almost $40 \%$ of provincial government revenues coming from federal transfers, primarily equalisation. This compares to Alberta at $10.5 \%$ (Finance Canada, 2007). New Brunswick has one of the highest unemployment (9.3\%) and lowest employment rates (58.5\%) in the country (Statistics Canada, 2010). Over the past decade, the northern rural areas of the province have been significantly impacted by downturns in the fishing and forestry sectors and have struggled to replace the jobs lost by plant closures. In contrast, the more urban south has been booming, drawing benefits from a long-term diversification strategy started years ago. For that reason, the OECD study tour visited both Moncton, an urban area experiencing growth, as well as Miramichi, an area hard-hit by plant closures and out-migration. At the Miramichi round table, it was noted that 2000 people from Miramichi alone were working in Fort McMurray, Alberta. New Brunswick has the second highest illiteracy rate in Canada; many jobs are seasonal and low-pay. Key provincial labour market goals are to assist New Brunswickers to acquire the skills and employment experience necessary to maintain full-time, long-term employment.

113. The province of New Brunswick was the second Canadian jurisdiction to sign a Labour Market Development Agreement in December 1996, after the province of Alberta. Unlike Alberta, pre-LMDA the province of New Brunswick had very limited provincial infrastructure in place that provided employment programming or career services to New Brunswickers. Federal staff who transferred to the province were initially integrated into the provincial Social Development department and, over time - through departmental adjustments and re-alignments - were transferred to the Department of Post-Secondary Education, Training and Labour (PETL). This process was characterised by one informant as, "devolution and then revolution", as the provincial government came to grips with their new responsibilities in the labour market as well as the opportunities it provided.

114. Labour market programmes and services are designed and delivered under the authority of the PETL Assistant Deputy Minister of Employment Development, who reports to the Deputy Minister. This contrasts with Alberta where programme design and delivery responsibility are under separate ADM direction. There are approximately 200 staff in the Employment Development Division, including seven 
regional directors offering 19 points of service across the province. Like AEI, PETL responsibilities include the labour function. Unlike Alberta, PETL responsibilities include the post-secondary education system, but do not include direct industry liaison or the provision of social assistance. The former is delivered by a network of 15 Enterprise Agencies across the province (with PETL as well as federal and provincial funding and support) and the latter by 20 Social Development offices. The provincial pot of money for employment services is relatively small - it is estimated that federal funding of approximately \$125.1 M for the LMDA, LMA and Economic Action Plan in 2009/10 constitutes over 85\% of PETL's employment programme funding ${ }^{23}$. However, like any other provincial government, in order to access these federal funds, provincial government departments must secure provincial agreement for the expenditure of federal funds, requiring provincial budget decision making and deliberation, often through supplementary estimates.

115. PETL staff estimate that $80 \%$ of their programmes and services are provided directly by departmental staff, with the balance outsourced, primarily to not-for-profit service providers. Internally, they provide employment counselling (case planning, return to work places) and most career counselling services. Targeted (e.g. youth, disabled) and specialised (e.g. resume writing, work search groups) services are generally outsourced, as well as activities needed quickly or where the necessary expertise is not available in house. In New Brunswick the "face" of employment services that the public sees is that of the provincial government, labelled as PETL Career Information Centres. Within this provincial worksite, in some cities (e.g. Fredericton), the actual services are provided by YMCA staff working under a longstanding contract with the province. Approximately $70 \%$ of New Brunswickers served by the provincial employment services are unemployed and receiving EI payments, while about 15-20\% are employed and either of risk of losing their jobs or wishing to upgrade their employment prospects. Only about $5 \%$ of those served by PETL are in receipt of social assistance. The balance of clients served (5-10\%) are unemployed and not in receipt of either EI or social assistance.

\section{Accountability Provisions of the Provincial-regional-local Relationship}

116. All labour market programmes and services delivered by PETL staff and their service providers are governed by provincial legislation, regulation or policy. As identified in Box 5, there are five key programmes which provide the overall policy framework, each with dedicated accountability provisions. 


\section{Box 5. New Brunswick Employment Development Programmes}

Work ability provides wage subsidies to eligible employers for unemployed individuals who have an employment action plan.

Workforce Expansion provides wage supplements to eligible employers as well as financial support to eligible individuals to start their own business.

Training \& Skills Development assists case managed individuals to access appropriate training and education programmes.

Student Employment and Experience Development provides post-secondary students with employment experience.

Employment Services provides a variety of employment services to targeted clients. This includes employment assistance services, adjustment services and research and innovation.

117. For each of these programmes - which have not changed substantially since the LMDA was signed in 1996 - there are detailed descriptions of what can be provided to whom (objectives, eligibility, rules and regulations), as well as defined service delivery parameters (access, roles and responsibilities, procurement options, tendering, payment procedures, etc.). These ensure that appropriate legal and financial accountability controls are followed. Many of these programmes were initially developed on the basis of ensuring the test of similarity to federal programmes, as prescribed by the federal Employment Insurance legislation. New Brunswick has also identified key target groups for labour market programming - immigrants, people with disabilities, Aboriginal persons, new entrants to the labour market and older workers. There are separate agreements with the Government of Canada that provide federal contributions to provincial programmes for older workers (TIOW) and persons with disabilities (LMAPD) ${ }^{24}$.

\section{Degree of Flexibility that New Brunswick Regional and Local Offices have to Manage Programmes}

\section{Strategic Approach, Programme Goals and Programme Design}

118. Given electoral change, political strategic direction in New Brunswick changes more frequently than in Alberta, where the same party has been in power since 1971. The Liberal party was in power in New Brunswick when this study was undertaken; they took over from the Conservatives in 2006 under a platform titled "Charter for Change". This outlined key government directions and has been supplemented each year by mandate letters from the Premier to each Minister. In 2007, the Liberals released their "Action Plan to be Self Sufficient in New Brunswick", based on a public consultation process and recommendations from a self-sufficiency task force. One of the key thrusts is to transform the workforce, including training for the new economy, continuous learning, opportunity for all, and increasing the population by reversing the outflow of people and increasing immigration. A key objective is for the 
province to be self sufficient by 2026. In effect this means that the province would no longer receive federal equalisation payments.

119. The overall PETL departmental strategic plan, which expired in 2009, is in the process of being renewed. However, there are other processes that provide the department with strategic direction. In October 2008, a Skills Summit Working Group reported and held a Skills Summit to discuss specific actions that would meet the ever-changing labour force needs of the province. Out of that process a "Minister's Standing Forum on Skills Development" was announced, as well as various working groups to deal with skills shortages. There have also been recent changes to the post-secondary education sector that moves it out from direct government oversight. As part of this reform, New Brunswick has established permanent "Education and Industry Councils" throughout the province. These formalise collaboration to ensure that the education and post-secondary education sector within each region is aligned with and responsive to the labour market needs of the local business community. PETL regional directors sit on these councils as ex-officio members.

120. Although overall direction is provided by the PETL Assistant Deputy Minister and departmental policies, each PETL Regional Director relies heavily on their partnership with the 15 regional Enterprise Agencies to help them identify which employers and labour market information needs to focus on. These federal/provincial/municipal funded community economic development organisations are expected to lead in the development of strategic plans for their geographic area, including co-ordinating labour force development initiatives. The PETL regional directors are expected to sign off on the work plans of the Enterprise Agencies in their regions, and pay special attention to the work plans of the Labour Force Development Officers as PETL provides this funding. In addition, each year there are two to three centrally-led sector strategies that PETL staff participate in and that provide direction with respect to a specific sector (for example, forestry, translation services, and health care).

121. There are five well-established PETL programmes, and these drive all of the activities of the division. For each programme, there is a detailed description as well as defined delivery parameters. These detailed overviews take into account the terms and conditions of the federal funding, adapted to New Brunswick needs. While the programmes and services are developed by central office staff, this is done with considerable input from regional and local office staff, with over $81 \%$ of staff responding to the esurvey saying that they are able to influence provincial programming. The Employment Development Division is relatively small and connections between central, regional and local office staff occur on a frequent basis. For example, there are weekly teleconferences between the ADM and the regional directors, and face to face meetings with all central office and regional directors every two months. There has been little Regional Director turnover, providing an ongoing forum for problem solving, a strong organisational culture and ensuring an element of standardisation across the province. In addition, regional and local office staff sit on central office led committees and working groups that develop programme guidelines and parameters and their input has often resulted in programme changes.

122. PETL staff were asked to reflect on the changes brought about by devolution. Given the passage of time, most PETL staff have no personal experience with delivering similar programmes under federal leadership and control. A director from the community college sector recalled that, when the programmes were under federal control, the college used to do training for a block of federal students, and these students had to be a certain sex or age, with very strict guidelines on client eligibility. In contrast, 
programmes today can now be more customised to the individual, the guidelines seem to be very broad, and bending the rules is a lot easier to do. It is now more student focused, whereas in the past it was more institutional, one-size-fits-all focused. In the community college director's view, better outcomes are achieved when students choose the programme they want to take, as opposed to being slotted into spaces that are available and chosen by others.

123. Another PETL staff member commented that, before the LMDA, federal programmes were tailored to a national scope and decisions took much longer. Under provincial control, programmes can be more responsive to New Brunswick needs, and decisions can be made much more quickly. In addition, the decision-making process at the provincial level is more open as it is known who is actually making the decision; as a result there are more opportunities to intervene than when decisions were made in Ottawa. There is now a New Brunswick definition of underemployed, which was not the case pre-devolution.

124. In terms of New Brunswick programming, $80 \%$ of the respondents to the e-survey identified that there were labour market priorities in their region that could not be addressed through current PETL programming. The roundtable also exposed elements of dissatisfaction with the five PETL programs. Some respondents felt that they were not adaptable enough to rural needs, others mentioned that they were developed 20 years ago at a time of high unemployment and had not kept up to today's needs. Others noted that the most flexible and used component of the array was labour market research and analysis (a subset of Employment Services), and that perhaps funding should be shifted from under-used areas (for example, Workforce Expansion). On the other hand, many commented on the benefits of the additional flexibility brought about as a result of the LMA. Although New Brunswick still has the same five programmes as before, the LMA has helped PETL staff think outside the box and loosen the guidelines in order to ensure take up and that the money allocated is spent.

125. A consistent theme that came up in many of the comments in New Brunswick was the importance of having a standard suite of programmes across the province. While acknowledging that some flexibility is good, most also noted that accountability was as important. In such a small province where politicians are close at hand, all programmes need to be available across the province; otherwise there would be concerns over favouritism. All PETL staff seemed quite aware that they were primarily delivering federal programmes and that New Brunswick programmes were bound by federal programme parameters. Rather than granting additional flexibility to adapt programmes on a regional or local basis, PETL staff consistently preferred the idea of working together to change the overall provincial programme. However, given the dissatisfaction expressed through the e-survey and roundtables, the changes to provincial programming implemented with the LMA have not gone as far as many managers would like.

\section{Client Eligibility}

126. The regions work with everyone who is unemployed; however target groups are first defined through the federal-provincial LMDA and LMA, and then further refined through provincial target groups and within the parameters of the five New Brunswick programmes. It was noted that the flexibility made possible through the LMA that made PETL services available to a much broader group of citizens was welcomed, and New Brunswick has used this additional funding and the flexibility they already had in their programme guidelines to allow new groups to access programming. 
127. It was, however, also noted that there are still restrictions with how long people need to be out of school to be eligible for training, the amount of funding available for training, etc. In the e-survey, 50\% of respondents said that there were vulnerable groups that they could not work with or provide the full array of services to - for example, those with less than a grade seven education, those suffering from mental illness, and youth between 18-21. More than $10 \%$ of those coming in for services are not eligible for the full array of services on offer, such as training.

128. From the interviews, it appeared that an area where regions and local offices were seeking increased flexibility relates to PETL's ability to provide services to persons who are already employed. While the key focus of PETL programs is on the unemployed, $15-20 \%$ of clients seeking services are employed and either at risk of losing their jobs or wishing to upgrade their employment prospects. Regional staff would like to be able to provide enhanced services to anyone who is employed, but there are difficulties with counselling people to quit their jobs. The key issue is the quality of jobs, as people seek PETL approval for a quit so that they can access EI funding to return to school. Given that there are some circumstances where it may be appropriate for a person to quit their job and others where it is not, as outlined in Box 6 the province has developed their own definition of underemployment.

\section{Box 6. New Brunswick Administrative Guidelines for Defining Underemployed}

A client can be authorised to quit his/her employment and be considered eligible under the Training \& Skills Development (TSD) programme. In such instances, an employment action plan must be developed with an Employment Counselor. Normally, the client would contact the employment counselor prior to leaving his/her employment, however, TSD can still be considered after the fact so long as the individual would have been TSD eligible at the time he/she quit. Note that training should not have started.

In authorizing a quit, Employment Counselors must ensure that training is actually the intervention required to assist the individual in obtaining more suitable employment. Often times, in cases where individuals are deemed to be underemployed, further training is not the solution.

TSD funding will be made available only when the client demonstrates the need for training and that the learning intervention is likely to result in the client becoming self-sufficient.

Situations which warrant consideration are as follows:

- $\quad$ seasonal employment where training intervention will result in the client moving to year round employment or extending his/her seasonal employment;

- $\quad$ threatened by the possibility of a layoff;

- unable to perform the work due to health related reasons; (confirmation from medical profession is suggested);

- $\quad$ underemployed $^{*}$

*Note: In exceptional cases clients may be endorsed to leave jobs that are part-time, sporadic or low paying where client potential may lead to improved sustainable employment as a direct result of training. The return on investment must also be considered. The decision to authorise a quit due to underemployment must be approved by the Manager and be in line with labour market opportunities within the context of local and regional priorities. Low paying jobs are determined by using the Poverty Lines Chart issued by the Canadian Council on Social Development as a guide. Other elements to consider when approving a quit are: local job market, going rate provided by employers, occupations in demand, industry growth, fields in which we are currently funding training, reach back history. 
129. While perhaps not flexible enough to meet all PETL staff wishes, it is nevertheless noteworthy that the definition of underemployment can - post-LMDA- be determined at the provincial (not national) level, and further refined at a regional or local level. Staff at the roundtables also noted that they had successfully developed a local programme for people with special needs, despite the restrictions outlined in the provincial programme frameworks. These are all examples where the regional and local offices have been able to make provincial eligibility rules and guidelines more flexible to meet the needs of New Brunswickers.

\section{Performance Measures and Targets}

130. The federally determined performance measures in both the LMDA and LMA are used by PETL regional and local staff to measure outputs and outcomes. For the LMDAs, targets are first set at the provincial level and then rolled-up at the federal level and added to the federal annual plan. In addition to these federal-provincial performance measures, PETL has developed 27 indictors of performance, with five major ones. Their systems and reports provide results based on these measures; these have emerged from many years of experience and historical data. Although regional and local office staff did not provide input into the performance measures in the federal-provincial agreements, it was acknowledged that central office PETL staff did, using the intelligence secured from regional and local staff work on provincial performance measures. It was also acknowledged that while measures are important to focus the work, only some are useful - these include how many employability assessments are done, the size of the caseload being held by employment counsellors, the ratio of open to closed cases, and how many individuals find employment.

131. In terms of the targets under the measures, these are set by each PETL region, and $64 \%$ of those surveyed viewed them as open to negotiation. In the beginning of the LMDA, the targets were set by central office, however, in the fourth year each region and local office began to set their own targets. These are then rolled up into a provincial target set by the province in co-operation with Service Canada staff. However, it was also acknowledged that with the changes to Service Canada federal managers have become increasingly disengaged and unaware of what their role in the process is supposed to be ${ }^{25}$. For the LMA, the priorities are client groups, not targets per se, and there is no requirement that they be jointly set on a federal-provincial basis. These priorities are set collectively by the PETL central office, regional and local office managers on an annual basis.

132. Although targets appear in each manager's performance agreement, there are no real sanctions if PETL managers do not meet the targets set. Through the reporting process (which includes follow up telephone surveys), all staff across the province can see how their region or office compares to others. If the targets are not met, the key response is to figure out why. The main place where the targets appear publicly is in the annual Canada-wide EI Monitoring and Assessment Report, where New Brunswick outcomes are integrated into Canadian results. Provincial staff have an opportunity to negotiate the contents of the New Brunswick portion of this national report before it is publicly released. LMDA results organised on an Atlantic, as opposed to a New Brunswick basis. 
are also identified against targets and reported in the PETL Annual Report. It is common for LMDA targets for New Brunswick to be met or surpassed.

133. PETL regional and local offices are not benchmarked against each other, but information is shared on the results achieved across regions and offices. Although there is no direct comparison, each office looks at how they performed in relation to their counterparts. Those interviewed identified that it was difficult to compare across regions and offices as there are such significant differences - for example, the cities are booming, each with its own particular sector that is strong. In the northern part of the province fishing and forestry - which have been the mainstay in the past - are declining and there is outmigration to other parts of the province and out of province. The PETL regional directors discuss the results overall and try to understand why there are differences at their regular meetings.

\section{Collaboration and Partnerships}

134. The interviews and e-survey identified that PETL staff partner extensively with a wide variety of organisations, often through formal arrangements. The highest level of collaboration was between government departments, followed by colleges, then economic development agencies. All who responded to the e-survey acknowledged that collaboration had a significant impact on programming. PETL is a very popular partner as they have federal money to spend on both clients and collaboration activities. On the other hand, the roundtable noted insufficient funding available for facilitating partnerships, that there is programme but not facilitation money available. Partnerships work because the different partners bring money to the table.

135. PETL's most important external partnership is with the Enterprise Networks, where PETL regional directors meet on a regular basis with agency employees, secure input into their strategic direction through this process, and feed their results and statistics into the Enterprise Agency's annual report. Some of the Targeted Initiative for Older Workers projects are run by the Enterprise Networks, with PETL staff referring clients to the four approved projects. In order to secure industry information and consultation, PETL funds the salaries of the Labour Force Development Officer positions in the Enterprise Agencies under a defined contractual agreement. This is clearly an example of horizontal accountability as promoted by the OECD. PETL staff are in regular contact with Labour Force Development Officers in each Enterprise Agency. 


\section{Box 7. Labour Force Development Officer (LFDO)}

This is professional administrative and co-ordination work in the field of Labour Force Development. Work involves the co-ordination of labour force development activities with regional partners. The LFDO provides advice and guidance to the Community Economic Development Agency in the work plan process and provides information and advisory services to local small and medium-sized enterprises (SMEs) and community groups. Work also involves the promotion and support in the delivery of government programmes and services to SMEs and community clients through collaboration with government partners. Work also involves identifying and assessing regional employment related barriers including personal, social, health, education and work experience issues as part of the regional strategic planning process. Work also involves responsibility for establishing effective linkages with other service providers. In addition to the above-noted duties, employees of this class may be responsible for the co-ordination of community resources in a region. In this case, work involves responsibility for identifying organisations that will undertake activities; liaising with community organisations on matters affecting the labour force development of the region; co-ordinating the approval of and providing support services to strategic projects; and ensuring stakeholder involvement in regional labour force development activities.

Although employed by the Enterprise Networks, there are defined relationships with PETL staff:

- $\quad$ LFDOs will provide linkages to employers, whom they have determined as requiring the services of PETL's Programme Consultants. PETL will then decide on the direction to be taken regarding the HR issues brought forward.

- $\quad$ LFDOs will work in co-operation with PETL's Programme Consultants in ensuring local companies are continuously informed of HR trends and local developments, activities, tools and support.

- LFDOs will work in co-operation with PETL's Programme Consultants in enhancing awareness of local companies HR planning requirements.

- LFDOs ensure that their clients are made aware of PETL's programs and services by providing them general information and referring them to the appropriate contacts at PETL's regional office.

136. PETL also partners with the regional Education and Industry Councils, as well as with individual colleges and post-secondary institutions through a regional co-ordinators group that meets regularly. There are defined processes to meet with Service Canada on LMDA, EI, youth, and disabled issues. The provincial LMDA committee meets three to four times per year where all federal and provincial projects are outlined and attempts are made to co-ordinate them. Recent challenges include the new federal initiatives regarding long-tenured workers and the stimulus funding, especially since PETL has to approve EI clients entering training. Since 2007, there has been a defined partnership with the Department of Social Development called Transition to Work, to assist work ready social assistance clients back to work. Clients are case managed with PETL contracted Work Service coaches, and for some clients participation in employment programming is now mandatory.

137. There are apprenticeship partnerships on reserve with First Nations chiefs. The depth of this partnership varies from one location to another. PETL is trying to reach out through job shadowing, and with the colleges have set up information centres on reserve. Regional directors also noted partnerships with third party contractors for job placement services for immigrants, persons with disabilities, and those leaving prisons. PETL staff sit on a steering committee with the health authorities in relation to 
homelessness issues, and individual regional directors partner with the school districts on school dropout issues.

138. The interviews identified that most partnerships were initiated at the regional or local level, and that the regions do not look to central office to give them direction. Indeed, people in Miramachi felt that the region is as resilient as it is due to partnership working. There are however, times when central office gives direction (e.g. with the Transition to Work programme for social assistance recipients). The Enterprise Networks are expected to take the lead role in partnerships with employers and industry. Partnership working is a big part of the PETL performance management system, and it was acknowledged that relationships were how programmes worked.

139. In terms of co-location, a number of offices had been co-located with Service Canada and other provincial Ministries at the start of the LMDA; however, the co-location with Service Canada has been diminishing over time as space needs, office arrangements, and mandates change. For example, in both Moncton and Fredericton, PETL was asked to leave the Service Canada offices and is now operating in conjunction with other provincial services. It was noted that when PETL staff were co-located with Service Canada and Social Development, it helped EI and social assistance clients be more aware of the employment services that were available to them, and also enhanced information sharing between federal and provincial staff. Service Canada has moved towards a one-window service for federal programmes from a one-window service for employment programmes. PETL staff also noted a disconnect with Service Canada staff working in New Brunswick and HRSDC in Ottawa, especially in relation to the EI changes being implemented through the federal stimulus money.

\section{Budgets and Financing}

140. Money is first allocated to the province through the federal-provincial process, and then is allocated to each PETL region, with each region and local office assigned a budget. There is some funding retained at central office for labour market research and analysis that provides a pool for new developments. Regions are free to move the money from one office and programme to another, as well as between programmes and regions, and manage to the bottom line. $70 \%$ of respondents to the e-survey identified that they had adequate flexibility with regard to budgets. For these respondents, a key objective is to ensure that all the funds allocated to the province are spent; historically, New Brunswick has overspent their LMDA allocation, which means that the province has contributed to the shortfall.

141. The interviews did not expose problems with a lack of resources, as the additional federal money was welcomed. PETL's key source of funding for employment programming is the Government of Canada through the various federal-provincial agreements. One interviewee noted the requirement for audits through the LMDA and LMA was sometimes problematic, given that there are a number of new agreements with additional auditing requirements. A particular complexity was identified in regards to auditors being expected to assure through the additional LMA funding that federal dollars has not displaced provincial dollars. This goes beyond what auditors are normally expected to judge and will be challenging. 


\section{Staffing and Outsourcing}

142. PETL regional and local staff have the full responsibility to hire and outsource, and do not require central office involvement or approval. Staff roles can be adjusted to some extent within the confines of the collective agreement. For example, regional directors cannot move staff from a counsellor to a programme role as there are collective agreements for employment counsellors. The restriction is not central office control, but the unionised environment in which they function. 50\% of those who completed the e-survey noted this restriction on outsourcing. When vacancies arise, staff can be assigned to another area, and the ADM is kept informed.

143. As previously noted, PETL outsources when they do not have the experienced people in house or if the services required are more intensive. Regions can create contracts as they see fit; they examine their client needs and the expertise of their staff resources and proceed accordingly. Most outsourcing is to notfor-profit agencies and most contracts are regularly renewed. PETL managers can single source to NGOs without going to tender with the Minister's approval. It was acknowledged that some of these contracts are politically charged since contracts have been there for years, resulting in an entitlement mentality. It is very difficult to close down such contracts or change the nature of the service provided. PETL regional directors discuss this regularly to ensure consistency across the province, and are very careful about contracting something out in the first place due to these outsourcing downsides.

144. One of the service delivery providers provided an interesting contrast between contracting with PETL and Service Canada. They have been contracting with PETL since 2003 to provide employment services for adults with intellectual disabilities, and also have a current contract with Service Canada to provide programming for 7-10 youth with intellectual disabilities. In the federal contract, they have to reapply for funding every six months, whereas with the province the funds can be committed for a longer period of time as it is part of PETL's ongoing mandate. Compared to Service Canada, PETL officials are much more direct, communicate face to face, have more flexibility, and there is less bureaucracy. The service provider noted that when contracting with Service Canada there are many layers and levels to get approvals and this significantly delays programme implementation. The federal contracting rules are also much more inflexible as they dictate line by line items that must be accounted for separately, and the agency is not allowed to move money around from one area to another. In contrast, when contracting with the province, the agency can decide how to allocate their resources internally without additional approval processes from the province. This reflection was not only heard in New Brunswick - an Alberta service provider noted that they had abandoned attempts at securing federal funding because of the more restrictive contracting environment.

145. The PETL staff interviewed, as well as those who completed the e-survey ${ }^{26}$ noted only marginal impact from the economic downturn over the past year as the province had felt the economic downturn three to four years earlier due to the downturn in the forestry and fishing sector. EI and social assistance caseloads increased only marginally, and there are lots of jobs: construction in particular is booming. The community college sector has expanded, with a plan to add an additional 1400 student seats in 2011. Other 
than relatively skilled employed clients anxious to leave their jobs and further upgrade their skills, PETL staff are not really seeing new or different clients as a result of the economic downturn.

146. The additional federal money through the Economic Action Plan has provided New Brunswick with the funds they require to meet their needs. Indeed, the challenge is spending the money that has been allocated, especially within the allocated time frame, as the funding it is time limited. Given the availability of this additional funding, intakes have increased $76 \%$, resulting in considerable increased staff activity and some delays in seeing clients. Since the provincial government needs to get supplementary estimates approved before the federal money can be spent, this sometimes also causes delays. However, the province is willing to undertake whatever actions are necessary to get the funds and people moving in a positive direction, including changing provincial programme guidelines if necessary to make more people eligible for labour market programming. They have succeeded in this such that all the extra federal stimulus money for this fiscal year has now been committed.

\section{Analysis of the Balance between Flexibility and Accountability with Respect to the Provincial- Regional-Local Relationship in New Brunswick}

147. PETL regional directors who were interviewed saw a good fit between the national, provincial priorities and their regional and local needs and priorities. They consider that their offices have a "very good" to "excellent" ability to be able to respond to local and regional priorities. In their view, the regions have considerable flexibility within the constraints of existing budgets, which have been growing. Examples were given of plant closures and how different regions have been able to customise their response.

148. This positive view obtained through the face-to-face interviews was somewhat moderated by the responses to the e-survey, where 55\% said they had a high degree of flexibility, $27 \%$ felt that flexibility was moderate and $18 \%$ felt that it was low. $80 \%$ of respondents identified a problem in their region in addressing local priorities through PETL programming. Although $90 \%$ identified that they worked with local agencies to develop local strategies, only $64 \%$ felt that they could contribute fully, while $36 \%$ felt that they could contribute only marginally.

149. Strategic goals for PETL are significantly influenced at a regional or local level through the Enterprise Agencies, and PETL has ample opportunity through flexible programming to respond to the goals of the Enterprise Agencies. Although it was noted that programme design, client eligibility and performance measurement of PETL programs are defined by central office, it was also acknowledged by all that regional and local staff have ample opportunity to provide input into these province-wide rules and regulations. If there was an aspect to improve, it would be through providing increased flexibility regarding eligibility.

150. In principle, PETL regions and local offices have considerable flexibility in terms of moving budget dollars around, and in terms of deciding between in-house and outsourced services. However, in practice, outsourcing is constrained by collective agreements and the fact that out-sourced contracts are mostly held by not-for-profit agencies through historical arrangements that are very difficult to change. Those who completed the e-survey would like greater flexibility with outsourcing. PETL regions have a high degree of flexibility in terms of collaboration and partnerships. In addition to informal arrangements, there seems to be a relatively high degree of institutionalisation through standing committees, indicating a 
view that formal arrangements are better than ad-hoc, informal connections as they build improved understanding over time.

151. New Brunswick maintains accountability through the legal, financial and administrative controls embedded in the five provincial programmes. Democratic accountability is enhanced through the standing committees and defined processes that allow for stakeholders and partners to influence PETL programming. Given the contracting arrangements in place and a greater dependence on the not-for-profit sector, PETL staff demonstrated accountability to their service providers, especially those with longstanding arrangements. As in Alberta, political accountability for PETL is the same as for any other provincial department, and there was no sense of accountability to other provincial governments or citizens in other provinces. Indeed, New Brunswickers are dismayed that many of their citizens have been forced by economic circumstances to move out of the province.

152. One consistent thread through the New Brunswick interviews, e-survey and round table commentary was not a call for enhanced flexibility, but rather a call for ensuring a level of consistency in programming across the province. This may be due to the small size of the province, where if there is inconsistency it is easy to detect and often highly politicised. PETL regional directors noted that they often took calls from the Premier and his office; therefore the rules and their consistent application were important.

153. A second consistent thread was an acknowledgement that the programmes PETL and their contractors are delivering are primarily federally funded, and also a sense of a stronger federal presence in day-to-day programme decisions through local Service Canada staff involvement in joint committees. This is not surprising given the province's overall greater dependency on the Government of Canada through the equalisation programme. There was not the same strong sense of reporting to citizens as was evidenced in Alberta, and reporting to the Government of Canada did not raise the same concerns. Given this context, it was interesting to note that the PETL LMA report tabled with the Government of Canada was not a dedicated document highlighting the agreed to performance indicators, but was instead just the departmental annual report. 


\section{KEY POINTS FROM THE EXAMINATION OF ACCOUNTABILITY AND FLEXIBILITY IN ALBERTA AND NEW BRUNSWICK}

154. There are many similarities between Alberta and New Brunswick in how they manage labour market programmes at the regional and local levels, and how regional and local offices are held accountable. First, each province presents a strong presence to their citizens with regard to the provincial labour market programmes and services on offer - in Alberta through 59 Labour Market Information Centres (LMICs) and Career Services Centres and in New Brunswick through 19 Career Information Centres. In neither province did the informational literature reviewed acknowledge a federal contribution to programming. There is a similar organisational structure with an ADM responsible for programme delivery supported by regional directors and a network of local offices dispersed throughout each province. There is a similar array of programmes on offer with similar target groups, structured initially around the LMDA parameters and now expanded to serve additional clients as allowed through the LMAs. It is noteworthy that Alberta never chose to offer a targeted wage subsidy programme, while New Brunswick always has. It is also noteworthy that with the additional LMA funding, both provinces used their existing platform of programmes and services on which to build, tweaking and expanding already existing parameters and guidelines. Although both provinces serve the same array of client groups, in each there is a difference emphasis - for example, in Alberta the needs of Aboriginal people and immigrants were highlighted, while New Brunswick places a particular emphasis on the underemployed.

155. Given the federal parameters, each province manages the programmes through defined envelopes and defined performance measures and targets where provincial measures are added to those prescribed by the Government of Canada. Their legal and financial accountability and reporting approaches are relatively similar, including routine use of annual plans and reports. Although the Alberta annual planning process is more structured than New Brunswick's, each is embedded in a standard provincial budget process that also requires departments to issue annual reports on programme outcomes and results. Although both jurisdictions use performance measures and targets, in neither does this go beyond the provincial level to direct action at the regional and local level. Benchmarking and comparisons between local and regional offices is informal and does not constitute a significant focus of central office oversight. Both provinces have strong ongoing connections with industry stakeholders in the labour market field. In both, the strong relationship with the federal government that resulted in the initial co-location of employment services with the federal EI programme has diminished significantly over the past decade with the establishment of Service Canada.

156. The differences are more subtle and often harder to detect without a detailed review such as provided through this study. While the Labour Force Development Officer role in New Brunswick is very close to the Business and Industry Liaison role in Alberta, a noteworthy distinction is where the position is located. In Alberta, it is within the AEI Ministry as a core business line, while in New Brunswick it is 
within the Enterprise Agency, a not-for-profit organisation funded from, and controlled by, multiple sources. Another difference is the involvement of the Government of Canada in the New Brunswick Enterprise Agencies, whereas in Alberta, the Regional Economic Development Agencies are funded and managed solely by the provincial government. In New Brunswick, the PETL regional directors get their strategic direction from the department as well as from the Enterprise Agencies, whereas AEI regional staff get theirs solely from departmental frameworks. In Alberta there is more emphasis on departmental strategic directions and province-wide strategies than in New Brunswick. There are significant differences in the proportion of provincial funding being managed by AEI and PETL regional directors: 50\% in Alberta vs. $20 \%$ in New Brunswick. This clearly explains the greater New Brunswick openness to acknowledging and highlighting the presence of the federal partner. There are differences in both the use of service providers and where they come from. Alberta focuses primarily on for-profit providers and outsourced delivery, while New Brunswick focuses more on the not-for-profit sector and internal delivery by provincial government staff. A big difference is the array of services contained within the two departments, which impacts the degree to which partnerships external to the department are required. While both AEI and PETL encompass all the programmes focused on in this study, AEI also encompasses social assistance, immigration and labour programmes. In contrast, PETL does not provide social assistance or immigration programmes, but does incorporate post-secondary education. However, in April 2010 PETL took on responsibility for the immigration function.

157. What is noteworthy about these similarities and differences is that, with the exception of performance measures and envelope financial allocations and reporting, these parameters are determined by the provinces themselves. With the introduction of the LMAs (which removed some of the restrictions prescribed by the LMDAs), provinces and territories now have almost complete freedom to make all the choices identified above based upon their own decision making.

158. While in both jurisdictions strategic direction, programme design, client eligibility and performance measures are all determined at the provincial level, in both systems regional and local staff feel that they have ample opportunity to shape the programmes and services they are delivering. The amount of flexibility provincial offices delegate to their regional and local offices is very similar in both jurisdictions. Indeed, New Brunswick may be more constrained due to the decision they have taken to keep more services in house and their contracting primarily to the not-for-profit sector. Although Alberta's RFP process and more competitive bidding process may mean that it takes additional time to let a contract in the first place, it provides them with increased flexibility when it comes time to terminate or renew a contract. 


\section{ACCOUNTABILITY AND FLEXIBILITY IN NINE OTHER CANADIAN PROVINCES AND TERRITORIES}

159. Since signing and implementing their LMDAs over 13 years ago, Alberta and New Brunswick have customised how they design, organise and deliver the former federal services to the particular needs and circumstances that prevail within their jurisdictions. Likewise, the eleven other Canadian provinces and territories that have now taken on the federal programming, assets and staff have had to make similar decisions as to how to integrate the federal programming into pre-existing P/T arrangements. They also needed to make subsequent decisions on how to integrate the additional federal LMA, Economic Action Plan, and TIOW funding on offer. Table 2, below, identifies the timeline in each Canadian jurisdiction that triggered this realignment of federal and provincial/territorial programmes and services. P/Ts are at very different stages. Some like Alberta and New Brunswick have mature governance systems, while others like Newfoundland \& Labrador, Nova Scotia and Prince Edward Island are currently in the process of integrating federal employees and re-designing programmes.

Table 2. LMDA Timetable

\begin{tabular}{lll}
\hline \multicolumn{1}{c}{ Jurisdiction } & LMDA Signature Date & LMDA Implementation Date \\
\hline Alberta & December 6, 1996 & November 1, 1997 \\
\hline New Brunswick & December 13, 1996 & April 1, 1997 \\
\hline Manitoba & April 17, 1997 & November 27, 1997 \\
\hline Québec & April 21, 1997 & April 1, 1998 \\
\hline Saskatchewan & February 6, 1998 & January 1, 1999 \\
\hline Northwest Territories & February 27, 1998 & October 1, 1998 \\
\hline Nunavut & May 11, 2000 & April 1, 2000 \\
\hline Ontario & November 23, 2005 & January 1, 2007 \\
\hline British Columbia & February 20, 2008 & February 2, 2009 \\
\hline Nova Scotia & June 13, 2008 & July 1, 2009 \\
\hline Newfoundland and & September 5, 2008 & October 1, 2009 \\
Labrador & September 5, 2008 & October 1, 2009 \\
\hline Prince Edward Island & July 8, 2009 & February 1, 2010 \\
\hline Yukon & S
\end{tabular}

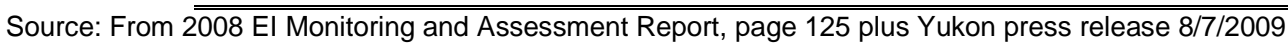

160. In order to improve the pan-Canadian dimensions of this OECD project, using contracted resources, HRSDC undertook an environmental scan of interesting and relevant examples of new types of flexibility and accountability being experimented with in Canadian jurisdictions beyond Alberta and New Brunswick. The examples do not present an overview of how active employment measures are designed and delivered in each P/T. Nine jurisdictions chose to participate and put forward a wide array of programmes or projects for review, ranging from highly specialised and targeted programmes for specific 
client populations to broad-based P/T-wide programmes or policy frameworks. The contractors (DC Strategic Management) provided criteria for the selection of projects and conducted interviews primarily with government employees in order to measure practice at the ground level. They used the OECD flexibility criteria to shape their inquiry and results. The projects that were reviewed are summarised in Table 4.

\section{Examples of Flexibility in Labour Market Policy}

Table 3: Selected Examples of Flexibility in Labour Market Policy (DC Strategic Management 2010)

\begin{tabular}{|c|c|c|}
\hline Jurisdiction & Name & Description \\
\hline British Columbia & Bladerunners & $\begin{array}{l}\text { Provides highly marginalised at-risk youth with job preparation and } \\
\text { job readiness skills, as well as work-place training. }\end{array}$ \\
\hline Saskatchewan & $\begin{array}{l}\text { Workplace Essential Skill } \\
\text { Saskatchewan (WESS) }\end{array}$ & $\begin{array}{l}\text { Provides an alternative for obtaining foundational skills through } \\
\text { partnerships between industry, an employer, and a training } \\
\text { institution. }\end{array}$ \\
\hline Manitoba & $\begin{array}{l}\text { Policy Framework- Focus } \\
\text { on Immigration }\end{array}$ & $\begin{array}{l}\text { Focuses on strategic linkages between departments and co- } \\
\text { ordinated services at the local level. }\end{array}$ \\
\hline Ontario & Job Connect & $\begin{array}{l}\text { Assists those at risk of continued or long-term unemployment to form } \\
\text { an attachment to the labour market (i.e. non-El eligible) through } 132 \\
\text { points of service. }\end{array}$ \\
\hline Québec & Emploi- Québec & $\begin{array}{l}\text { The Public Employment Service is composed of province-wide } \\
\text { central units, } 17 \text { regional directorates, } 145 \text { local directorates, totalling } \\
4,500 \text { full-time equivalent employees. }\end{array}$ \\
\hline Nova Scotia & $\begin{array}{l}\text { One Journey Work and } \\
\text { Learn }\end{array}$ & $\begin{array}{l}\text { Provides opportunities for skill development and direct employment } \\
\text { to Income Assistance/Employment Insurance recipients, and the } \\
\text { unemployed or the underemployed. Tied to industry shortages. }\end{array}$ \\
\hline $\begin{array}{l}\text { Newfoundland \& } \\
\text { Labrador }\end{array}$ & $\begin{array}{l}\text { Bridging the Gap- from } \\
\text { Education to Employment }\end{array}$ & $\begin{array}{l}\text { Provides } 40 \text { weeks of workplace essential skills learning using a } \\
\text { combination of classroom and workplace based learning. }\end{array}$ \\
\hline $\begin{array}{l}\text { Prince Edward } \\
\text { Island }\end{array}$ & Workplace Resources & $\begin{array}{l}\text { Provides Employment Officers to assist individuals to seek and find } \\
\text { employment. }\end{array}$ \\
\hline Yukon & Community Training Fund & Provides funding to training projects and individuals. \\
\hline
\end{tabular}

161. In terms of strategic approach, Ontario's Job Connect planning process provides an example of the integration of planning processes, performance management, and stakeholder involvement. The process is driven by a provincial framework that has been developed over a number of years with the participation of stakeholder groups. Service deliverers are consulted on the development and continued refinement of client risk profiles to determine client eligibility and to ensure that indicators are measureable. Smaller programmes studied, like those in British Columbia, Saskatchewan, Nova Scotia, Newfoundland \& Labrador and Yukon, were characterised by more informal planning processes that were largely reliant on the trust relationships between service providers, labour market partners and government employees.

162. In terms of programme goals and design, although the province or territory is responsible for the high-level programme design, the trend seemed to be to provide a programme framework rather than prescriptive details. The size of the programme or project studied appeared to make a difference - in the case of the large public employment services, the province was more prescriptive. However, in these cases the programme design itself incorporated opportunities for local feedback and flexibility. The contractors 
were told that defining client eligibility by source of income as is currently in place through many of the agreements (e.g. specific programmes focused on EI or social assistance recipient, older workers, immigrants, people with disabilities) was unhelpful. For example, Ontario has developed an alternative model with ten indicators that requires a client to exhibit at least three indicators to be eligible for programming. This means that those who receive labour market services in Ontario are slotted into programmes not by income source or characteristics but by their programming need. Developing these indicators took considerable effort on the part of Ontario government staff working with service delivery partners.

163. With respect to performance measurement and targets, there was little evidence of negotiated target setting in most of the studies. Targets were most often included in funding agreements and were a combination of client counts, activity counts and employment outcome measures. It was also noted that the role of the Auditor General and Provincial Auditors should not be underestimated in driving accountability requirements within provincial governments. It was clear to the contractors that the LMDAs and LMAs were influencing accountability requirements and performance management at the local level. Third party service delivery agreements were often performance based - that is, payment was based on client outcomes, thereby increasing the accountability of these agencies. It was noted that separate accountability requirements for the LMDAs and LMAs was perceived as onerous by P/T government staff, requiring a lot of work behind the scenes.

164. All projects highlighted the importance of collaboration and partnerships, especially with industry and post-secondary institutions. Criteria for the development of partnerships and networks was not prescribed by provincial governments in detail for many of the programmes studied, nor were they set out in funding agreements. Governance mechanisms were largely the invention or creation of local delivery agents working with provincial or territorial government staff. Often the form of the project's governance mechanism appeared to have grown and been determined by what was required locally to deliver the outcomes.

165. It was noted that some $\mathrm{P} / \mathrm{T}$ s had set up $\mathrm{P} / \mathrm{T}$-wide ongoing structures to receive stakeholder input on $\mathrm{P} / \mathrm{T}$ labour market programmes. Emploi-Québec is governed by the Commission des partenaires du marché $d u$ travail consisting of employer, employee, community and government representatives. In Québec, there are also 17 regional councils of labour market partners (expected to be leaders in workforce and employment issues in their geographic area) as well as sector-based workforce committees that define the development needs of their sector and produce and implement action plans in response to these needs. Likewise, Manitoba has recently established the Manitoba Advisory Council on Workforce Development, composed of representatives from industry (through Manitoba sector councils ${ }^{27}$ ), labour, post-secondary institutions and senior government representatives. Ontario has a Job Connect Advisory Committee, composed of service providers for adults, youth, and the colleges that acts as an "early warning system" to identify new issues needing a response. It is supported by a service delivery advisory group. 
166. The applicable $\mathrm{P} / \mathrm{T}$ programme design usually outlines the financial parameters under which local service deliverers operated. A combination of practices was noted in the programmes studied, varying from line-by-line budget requirements and limitations in moving funds between budget items to block funding. The Nova Scotia and Prince Edward Island projects relied on line item budgeting. The JobConnect programme in Ontario allowed service providers to move funds from operating into flow through funds, but could not move funds in the other direction. Québec allowed for intra-budget transfers. Saskatchewan provided a higher degree of flexibility by using block funding.

167. Many of the programmes outsourced service delivery to community-based organisations (i.e. non-profit organisations with local boards) or more institutionalised organisations (i.e. post-secondary institutions) thereby providing strong community relationships. The ability to leverage contributions from other partners was seen as a key advantage of community-based delivery. British Columbia uses First Nations service providers because of their ability to connect with the hard to serve youth who are the core clients for BladeRunners. Saskatchewan relies heavily on regional colleges and their post-secondary expertise to deliver workplace essential skills. Ontario's JobConnect is completely delivered through community organisations or colleges. Newfoundland \& Labrador uses a community-based organisation with significant economic development ties to design and deliver the Bridging the Gap programme. Additional flexibility was noted in that subcontracting by community-based organisations to locally connected service agents was allowed in the British Columbia and Newfoundland \& Labrador examples. This ensured that more local expertise with the local economy and local employers could be obtained.

168. The prevalence of outsourcing clearly suggests that $\mathrm{P} / \mathrm{Ts}$ believe that third parties can be more flexible in responding to issues than government staff. It was noted that third parties are not bound by the obligations of public service hiring practices. They often have a single focus or business line and can concentrate on quick responses that meet the needs of labour market partners. In many cases, they are closer to the community of clients they serve and, as a result, can connect with the hard to serve groups targeted in many of programme studies. With their ability to develop detailed understandings of local employer needs, third party contractors are well positioned to develop the trust relationships required to deliver effective employment programming.

\section{Recommendations Made in the Related Study}

169. Based on their review of the nine programmes considered in the study, the contractors recommended that Canada's labour market agreement architecture should be reviewed to determine if F$\mathrm{P} / \mathrm{T}$ agreements could be consolidated and the accountability processes simplified. They suggested that the agreements should be needs-based, and not structured as at present around the income source or personal characteristic of the clients being served. They highlighted the value of labour market intelligence and that it should be more broadly recognised and supported at a local level. In their view, the formalised labour market information system needs to be enhanced with this local labour market intelligence. The importance of evidence-based decision making and continuous improvement needs to be better recognised. The lack of capacity in remote and small population areas should be reflected in funding arrangements so that staff development and training can take place. System confidence with flexibility can only increase as staff gain experience and develop capacity. 


\section{How this Compares to the Alberta and New Brunswick Case Studies}

170. The information derived from the contracted HRSDC research in nine other Canadian jurisdictions is consistent with the more detailed case study information derived from the OECD research in Alberta and New Brunswick. Across Canada, it is at the P/T level that the overall strategic direction and high-level programme design is set. Most Canadian jurisdictions are pooling federal and P/T dollars into an integrated array of $\mathrm{P} / \mathrm{T}$ programmes that are accessible to all citizens based upon their needs, not on whether they are receiving EI or social assistance, or are disabled, an Aboriginal person, immigrant, young or old. As in Alberta and New Brunswick, other P/Ts use partnerships and collaboration extensively, although there are differences in the degree to which these are formalised through structured advisory committees. Different projects controlled finances in different ways, including the degree to which services were outsourced compared to being provided by P/T government staff in house. Like the data reviewed in the case study provinces, provincial staff in the nine other jurisdictions examined highlighted the need to review the architecture of the various F-P/T funding agreements, suggesting a need for consolidation and simplification of accountability processes. 


\section{ANSWERING THE STUDY QUESTIONS}

\section{What has changed with Implementation of the LMDAs and LMAs?}

171. How active labour market programmes are designed, delivered and managed in Canada has changed substantially since 1996. No longer does a network of federal offices operating across the country and reporting to a central government department in Ottawa provide a broad array of labour market adjustment services. Instead, provincial and territorial governments now operate Canada's national employment service. Taking on this responsibility has allowed them to align federally funded programmes with provincial/territorial, regional and local priorities and programmes. Many P/T governments used the opportunity presented by devolution to create a seamless, integrated workforce development service available to all their citizens. For some, this has meant reconfiguring and restructuring not only the previous federal and P/T labour market services, but also how they relate to other P/T responsibilities such as post-secondary education, social assistance, social services, and economic development programmes. With provincial and territorial governments now largely responsible for labour market programme design and delivery, the federal role has shifted to providing funding; ensuring accountability, evaluation and national policy priorities; and managing the national or pan-Canadian aspects of labour market development. To date they have also retained responsibility for youth, Aboriginal and some disability programming.

172. Devolution in Canada did not take place in an institutional vacuum, and how each province and territory has decided to integrate the federal resources, staff and assets that they received is very much rooted in their unique institutional setting and can vary significantly from one jurisdiction to another. However, all those interviewed for this study - in Ottawa, Alberta and New Brunswick - believe that devolution has improved the effectiveness of labour market programming in Canada, and that P/T governments (and their regional and local offices) have the necessary leadership and capacity to provide their citizens and employers with the services they require. The additional federal resources made available through the LMAs and the Economic Action Plan have also been enormously helpful.

173. Many noted that, with $\mathrm{P} / \mathrm{T}$ governments now responsible, policy development is a more collegial and iterative process within each $\mathrm{P} / \mathrm{T}$, as policy and delivery staff meet on a regular basis. Programmes can now be more customised to individual needs, whereas in the past there was a block purchase of programmes that individuals were fit into. Labour market programming is now more connected to $\mathrm{P} / \mathrm{T}$ political priorities and circumstances. Since programme design is under P/T control, there is a quicker response time, as well as a larger array of programmes and services than was previously available. Instead of facing two government funding bodies with different programme goals, programme parameters, client eligibility requirements, reporting requirements, operational targets and decision making processes, for-

profit and not-for-profit service delivery contractors are now presented with a unified and coherent 
government stance under $\mathrm{P} / \mathrm{T}$ government control. Those interviewed noted in particular their preference for dealing with $\mathrm{P} / \mathrm{T}$ governments over what they perceived as an inflexible, slow, remote and overly bureaucratic Service Canada.

\section{Where is There the Most Flexibility and Where is There the Least?}

174. Based on the analysis undertaken in this study, Table 5 below provides a summary of where the weight of decision making and control for labour market matters falls in the Alberta and New Brunswick post-devolution context, considered against the key flexibility dimensions identified by the OECD.

Table 4- Post-devolution- Where Does Control Lie?

\begin{tabular}{|c|c|c|c|c|c|}
\hline $\begin{array}{l}\text { Management } \\
\quad \text { Area }\end{array}$ & Federal & $\begin{array}{l}\text { Provincial/ } \\
\text { Territorial }\end{array}$ & Regional & Local & Comment \\
\hline $\begin{array}{l}\text { Strategic } \\
\text { approach \& } \\
\text { programme design }\end{array}$ & $x$ & $x$ & & & $\begin{array}{l}\text { Provinces translate federal directions into } \\
\text { provincial programmes, using input from their } \\
\text { regional and local offices as well as stakeholders. }\end{array}$ \\
\hline Client eligibility & $x$ & $x$ & & & $\begin{array}{l}\text { Previous federal restrictions limiting services to } \mathrm{El} \\
\text { clients have been significantly eased with the } \\
\text { LMAs. }\end{array}$ \\
\hline $\begin{array}{l}\text { Performance } \\
\text { measures \& } \\
\text { targets }\end{array}$ & $x$ & $x$ & & & $\begin{array}{l}\text { Measures are mostly determined at the federal } \\
\text { level, supplemented by provincially identified } \\
\text { measures. Targets are regionally defined. }\end{array}$ \\
\hline $\begin{array}{l}\text { Collaboration \& } \\
\text { partnerships }\end{array}$ & & $x$ & $x$ & $x$ & $\begin{array}{l}\text { The most extensive partnerships are at the } \\
\text { provincial, regional and local level. }\end{array}$ \\
\hline $\begin{array}{l}\text { Budgets \& } \\
\text { financing }\end{array}$ & $x$ & $x$ & $x$ & & $\begin{array}{l}\text { The segmented federal-provincial agreements and } \\
\text { funding envelopes constrain regional \& local } \\
\text { flexibility. However at the regional level it is } \\
\text { possible to move funds within the limitations of the } \\
\text { funding envelopes. }\end{array}$ \\
\hline $\begin{array}{l}\text { Staffing and } \\
\text { outsourcing }\end{array}$ & & & $X$ & $X$ & $\begin{array}{l}\text { Regional and local flexibility can be impeded by } \\
\text { collective agreements and provincial rules. }\end{array}$ \\
\hline
\end{tabular}

175. With the responsibilities that each P/T has assumed from the Government of Canada through the LMDAs, considerable power and authority in the policy domain has been retained at the P/T level and has not been passed down to the regional and local level. This includes responsibility for strategic direction, policy and programme design (including client eligibility) and how performance is measured. However, in both Alberta and New Brunswick, regional and local managers did not see the retention of policy and performance control at the provincial level as a big concern. They feel that they have ample opportunity to influence overall programme direction and design through the strong interactions that take place within the province, that there is a good mix of programmes that they can choose from, and that consistency of performance measures across the province is a very important principle. Targets are defined by regional and local actors, rather than the level of the P/T. Regional and local offices have the greatest degree of flexibility in deciding who they partner with and have extensive collaborative relationships. They can move budgets from one area to another within the limitations of the funding envelopes. When not 
constrained by collective agreements and existing contracts they can also choose when to outsource and when to offer a programme with departmental staff.

176. Devolution of active labour market programming through the LMDAs and subsequent federal funding through the LMAs has provided P/T governments with the flexibility to adjust policy at its various design, implementation and delivery stages in order to meet the needs of their particular labour markets. Especially since the LMAs were implemented (in 2008 in most P/Ts, and in 2009 in the remaining jurisdictions), there has been ample federal funding to meet a variety of needs, and the federal rules governing which programmes are to be provided, to whom and under which circumstances are sufficiently broad to allow $\mathrm{P} / \mathrm{T}$ governments to easily customise federally-funded programmes to their particular needs and integrate them with provincially/territorially-funded programmes. There are virtually no federal rules regarding who P/Ts should collaborate or partner with, or how they balance service delivery in terms of government delivery versus outsourcing.

177. Where P/T governments have the least amount of flexibility relates to the performance measures that are required under the agreements, how reporting is done, how the agreements are structured (including the fact that money flows through a number of segmented agreements), how the money gets assigned (including allocations from the EI account), and the formula used for its distribution. For changing the allocation model for the LMDAs, the main obstacle is that any changes to the model will benefit some provinces and territories and affect other jurisdictions negatively. Since all jurisdictions must agree when selecting the variables for LMDA allocation model, reaching a consensus on any changes to the allocation model is difficult. Although to date P/Ts have not expressed concern with the federally developed performance measures and reporting, the fact that promised LMA reports are not publicly available in the format and timing agreed to leads one to ask whether the performance measures are the right ones and whether provinces are having problems in securing the data. However, with the understanding that there was some flexibility in the reporting format, it is important to note that the LMA reporting process is new and that jurisdictions are working on data collection and processes to fulfill the performance measures and respond to the terms of the agreement. As with all new processes, there is an implementation phase in which potential issues and challenges are addressed.

178. In terms of how agreements are structured, officials from Alberta, New Brunswick and the Government of Canada interviewed through this research (as well as many consulted through the related HRSDC project) believe that some sort of consolidation and simplification of the current array of clientbased targeted F-P/T agreements is warranted. Rationalisation of the array of agreements (including the LMDAs, the LMAs, as well as the Targeted Initiative for Older Workers and the Labour Market Agreements for Persons with Disabilities [which are cost-shared]) could improve fairness in the system, allow for longer term strategic planning on a $\mathrm{P} / \mathrm{T}$ as well as a pan-Canadian basis, and improve transparency and accountability to citizens.

\section{Do Regional and Local Offices have Enough Flexibility to Respond to Local Issues?}

179. Regional directors in both Alberta and New Brunswick clearly believe that they have ample flexibility to respond to regional and local needs, and that they have been well positioned to respond to the recent economic downturn. Examples were given in both jurisdictions of how provincial guidelines and programmes could be adapted to their regional labour markets; that money can be moved between offices 
and regions; and that they can adequately respond to joint ventures with their partners at the regional and local level. Neither organisation is driven by provincially-set targets; indeed, it was acknowledged that consistent measures and targets are necessary, particularly in relation to third party contracting. When each jurisdiction was faced with a need to determine a policy on underemployment and access to training support for those already employed, it was provincial - not federal - rules that determined access to provincial programming as well as federal Part I EI benefits. Given the economic downturn, regions have been able to adjust the mix of programmes, and mount new programmes as they believe necessary for their labour markets. It was, however, acknowledged in Alberta that expanding existing contracts, as opposed to mounting new ones, is the preferred approach given the rigour of provincial requirements for third party contracting. Even though rigorous, this routine process does ultimately provide greater flexibility, a fact acknowledged by New Brunswick regional directors who are locked into third party contracts that over time are viewed by some contractors as an entitlement.

180. This view of adequate flexibility was not shared in all cases by their local managers who desired greater flexibility particularly with respect to client eligibility and budget management. In New Brunswick, local managers also felt that the provincial programmes on offer often did not meet their local needs. Local managers in both provinces also identified that they would like greater flexibility in outsourcing beyond the provincial rules and practices that have grown up over time.

181. This demonstrates that, even within a very small $\mathrm{P} / \mathrm{T}$, there can be considerable differences between local labour market contexts. For example, although New Brunswick is a small province by the number of inhabitants (around 750 000), it offers two different labour market situations: a more "urban" south where towns have been booming in recent years, drawing benefits from a long-term diversification strategy; and the less inhabited north which struggles to replace the jobs lost by local plant closures. While the two regions have different needs, the same labour market programmes are still implemented across the board.

182. At the same time, it does not appear advisable to recommend that Canadian P/Ts allocate more autonomy to local offices so that they can develop local programmes, as these offices simply would not have sufficient critical mass in terms of analytical and administrative capacity to design programmes specific to their areas. An issue for consideration therefore is whether to adjust the eligibility criteria for participation in programmes, with easier access to the programme in areas of higher unemployment. One approach would be for P/T governments to put some sort of formal waiver process in place that would allow for exemptions to P/T legislation and rules. This is the level where a waiver system would need to be established, given that in the Canadian context it is primarily the P/T (rather than the federal) level that is most prescriptive.

\section{Is there Enough Accountability to Satisfy Provincial/Territorial, National and Citizen Policy Concerns?}

183. Alberta views itself as a leader in accountability, with the annual departmental business plan the basis of all planning and reporting activities. Maintaining accountability is a high priority for Alberta, especially the legal, financial and administrative dimensions. While not as much of a focus in New Brunswick, the provincial government nevertheless has strong administrative processes in place to ensure that regional and local offices account for the expenditures they make, the programmes they implement, 
and that public money is spent for the purpose intended. Although there are challenges with the variety of reporting requirements under the different F-P/T agreements, each province has put mechanisms in place to fulfill their obligations to the Government of Canada. In neither province was accountability to provincial legislators an issue. In both jurisdictions, democratic accountability has been enhanced through processes each had put in place to consult with their citizens and stakeholders on the initiatives on offer and the subsequent reporting on outcomes through annual reports.

184. A strength of the two Canadian provinces - particularly Alberta - is the development of sophisticated performance management systems that do not rely on setting quantitative targets for local staff. This avoids some of the "perverse" effects that quantitative targets can have, for example, encouraging local offices to engage in certain activities just to "tick the right boxes" without a real eye to local needs. In Alberta, for example, system targets are very precise provincially, but only qualitative locally. Local staff are allocated broad strategic priorities (without specific targets) which they negotiate according to local needs. They then report back on the degree to which they have met these strategic objectives. The province also collects additional information on the programmes implemented/individuals served and employment outcomes. There is therefore a great deal of feedback in the Alberta system, but all the problems and perverse incentives created by overly stringent output targeting for front line staff are avoided. In order to be effective, such an approach requires a great deal of experience and self-confidence from senior managers, and strong capacities and loyalty from local staff. It also requires good ongoing communication, which is possible in the Canadian context as programme design and delivery has been decentralised and is now managed in defined geographic areas.

185. In brief, there do not seem to be any significant problems with ensuring enough accountability to satisfy the policy concerns of P/T governments. However, the same cannot be said as to whether there is enough accountability to satisfy national policy goals. The Government of Canada has chosen to implement this basket of programmes through P/T governments using a series of conditional - not block grants, the norm in most other social policy sectors in Canada. While an examination of the detailed funding agreements demonstrates that the legal, fiscal and performance provisions appear strong, less certain is whether all provinces and territories are actually reporting in a timely fashion and according to the agreed on framework. Given when the LMAs were implemented, P/T reports - as well as a national report according to the agreed on indicators - should all have been publicly available at the time this research was conducted, but were not. According to federal officials, all provinces and territories have provided the Government of Canada with performance indicator results as per their commitment under the LMAs. If they are late it is because many jurisdictions are still in the early implementation stage of their agreements. In the absence of a national report on the LMAs (or the other agreements noted in this review), that is available for public view, it is difficult to assess if Ottawa has the necessary information to adequately discharge their accountability responsibilities for the funding they are providing to $\mathrm{P} / \mathrm{T}$ governments under existing agreements.

186. Even if P/Ts have provided the necessary reports to the Government of Canada, this does not necessarily fulfill their accountability commitment to Canadian citizens. With the exception of the annual EI Monitoring and Assessment Report, none of the reports outlined in the bilateral agreements are national in scope. Instead there are a series of P/T reports on individual agreements. Given the reporting structure that has been selected it is almost impossible to get a pan-Canadian perspective on what P/Ts have done with the more than $\$ 2.45$ billion in federal funding that has been allocated on an annual basis for labour 
market programming through the LMDAs and LMAs. Added to this is the fact that P/T citizens are not aware of the degree to which the federal government remains vested in the policy area, given the low federal visibility provided in relation to signage on $\mathrm{P} / \mathrm{T}$ programming material.

187. To ensure democratic accountability, enhanced transparency is required. Citizens and stakeholders must be apprised of which order is government is responsible for the programmes that their taxes and EI contributions pay for, and they must also have access to comparable and reliable information so that they can assess how governments manage the designated programmes. Because the labour market policy domain is governed by bilateral F-P/T agreements, all announcements and information is publicised on an individual $\mathrm{P} / \mathrm{T}$, as opposed to a pan-Canadian basis.

\section{Could Horizontal Accountability Substitute for Vertical Accountability?}

188. There are two dimensions to this question - that of relationships between federal and $\mathrm{P} / \mathrm{T}$ governments in Canada, and that of relationships between P/T governments and their labour market partners within each $\mathrm{P} / \mathrm{T}$.

189. The idea that horizontal accountability between federal-provincial/territorial governments in Canada could substitute for vertical accountability in this policy domain is extremely challenging given the presence of conditional F-P/T funding agreements which by their very nature introduce a level of hierarchy and an imbalance in the relationship. Relationships can range along a spectrum from co-operative (informal, no goals are defined jointly, no planning together, information is shared as needed), to coordinated (some planning is required and more communication, thus a closer working relationship is developed), to collaborative (working together, having shared commitment and goals, developed in partnership) (AASL 1996). Collaborative relationships are inherently conflicted, as most ideas spring from the parties sharing differences, providing conflicting perspectives, and jointly working to develop a solution that meets all of their interests. The current F-P/T relationship as described in this study can be characterised as co-ordinated. For horizontal accountability to increase in the Canadian context, considerable work would need to be undertaken on a multilateral, as well as a bilateral, basis to engage in conversations that would move the relationship from co-ordinated to collaborative. Past F-P/T conflict in the policy domain has been avoided post-devolution. Part of the explanation is that until 2010 F-P/T arrangements were asymmetrical with both co-managed and devolved agreements in play. There may be new opportunities to develop more collaborative relationships now that all provinces and territories are operating under similar devolved agreements.

190. In terms of horizontal accountability between P/T governments and their labour market partners within each $\mathrm{P} / \mathrm{T}$, it is noteworthy that this was generally not considered as a viable alternative by regional and local delivery managers to vertical accountability within the context of their departmental structures. In Alberta, $82 \%$ of those surveyed noted that the strategic direction of their work is not done in conjunction with their partners, and only $33 \%$ would welcome this direction. The horizontal relationship in New Brunswick appears to be stronger, especially with respect to the Enterprise Agencies. In both Alberta and New Brunswick, new job roles have been developed to enable labour market officials to engage horizontally with a broad set of policy areas to solve problems. These new roles are the Business and Industry Liaison Officers (BILs) in Alberta and the Labour Force Development Officers (LFDOs) in New Brunswick. In this respect, the case study provinces are already implementing a key OECD LEED 
recommendation, which is to employ intermediaries to catalyse cross-sector policy responses, and think outside the box to solve urgent local problems.

191. What is less clear however is the degree to which collaboration on long-term strategic responses to local labour market issues takes place. This means that longer-term local employment goals are not being planned for, and the OECD research revealed a number of dysfunctions such as a lack of funding for longer-term, better quality job training, and the under-employment of Aboriginal populations. These problems could be resolved through the systematic development of governance linkages at regional and local levels and a more strategic joined-up approach locally. This would mean that the strong employment strategies, already developed at the P/T level, would be complemented by more specific strategies with cross-sector buy-in. 


\section{CONCLUSION AND CONSIDERATIONS FOR THE FUTURE}

\section{Canada's Revised Score Post-devolution}

192. Comparing the sub-regional flexibility available in Alberta and New Brunswick with that identified by the OECD for the co-managed P/Ts back in 2008, it is clear that there is now more flexibility available to provincial/territorial, regional and local managers under the devolved provincially/territoriallymanaged labour market system. While the co-managed P/Ts scored 2/5 in the international index of flexibility, Alberta and New Brunswick would today receive a score of 3/5 (see Tables $6 \& 7$ below).

Table 5: Score for Co-managed P/Ts in Canada under Federal Control in $2008^{28}$

\begin{tabular}{llcc}
\hline Management area & \multicolumn{1}{c}{ Description } & Score & $\begin{array}{c}\text { Total possible } \\
\text { score }\end{array}$ \\
\hline $\begin{array}{l}\text { Strategic approach \& } \\
\text { programme design }\end{array}$ & $\begin{array}{l}\text { Programmes designed at federal and provincial level. Service } \\
\text { Canada staff only informally consulted on the development of } \\
\text { programmes. }\end{array}$ & 0 & 1 \\
\hline Client eligibility & Eligibility decided centrally at federal/provincial level. & 0 & 1 \\
\hline $\begin{array}{l}\text { Performance } \\
\text { measures \& targets }\end{array}$ & Performance targets negotiated with local offices. & 0.5 & 1 \\
\hline $\begin{array}{l}\text { Collaboration \& } \\
\text { partnerships }\end{array}$ & $\begin{array}{l}\text { Local Service Canada offices have full responsibility for } \\
\text { negotiating individual agreements with local service providers. }\end{array}$ & 0.5 & 0.5 \\
\hline Budgets \& financing & $\begin{array}{l}\text { Service Canada regional offices receive line budgets and have } \\
\text { some freedom to move funding between them. }\end{array}$ & 0.5 & 1 \\
\hline $\begin{array}{l}\text { Staffing \& } \\
\text { outsourcing }\end{array}$ & $\begin{array}{l}\text { Local Service Canada offices have full responsibility for } \\
\text { negotiating individual agreements with local service providers. }\end{array}$ & 0.5 \\
\hline Total & & 2 & 0.5 \\
\hline
\end{tabular}

Table 6: Score under Alberta and New Brunswick Control 2010

\begin{tabular}{llcc}
\hline Management area & \multicolumn{1}{c}{ Description } & Score & $\begin{array}{c}\text { Total possible } \\
\text { score }\end{array}$ \\
\hline $\begin{array}{l}\text { Strategic approach \& } \\
\text { programme design }\end{array}$ & $\begin{array}{l}\text { Programmes are decided at provincial level but regional and } \\
\text { local offices are consulted. Local and regional offices lobby and } \\
\text { influence the provincial level through direct contacts and regular } \\
\text { meetings. }\end{array}$ & 0.5 & 1 \\
\hline Client eligibility & $\begin{array}{l}\text { Although some programmes are restricted to El clients, } \\
\text { considerable additional flexibility has emerged with the LMAs. }\end{array}$ & 0.5 & 1
\end{tabular}

${ }^{28}$ A brief outline of the methodology used for the OECD scoring is included in the Annex to this report. 


\begin{tabular}{llcc}
$\begin{array}{l}\text { Performance } \\
\text { measures \& targets }\end{array}$ & $\begin{array}{l}\text { Although performance measures are set federally and } \\
\text { provincially, targets are not translated to the regional and local } \\
\text { level. Measures are outcome, not output oriented. }\end{array}$ & 0.5 & 1 \\
\hline $\begin{array}{l}\text { Collaboration \& } \\
\text { partnerships }\end{array}$ & $\begin{array}{l}\text { Regional and local offices are fully able to decide who they } \\
\text { collaborate with. }\end{array}$ & 0.5 & 0.5 \\
\hline Budgets \& financing & $\begin{array}{l}\text { Provinces are constrained by federal budget envelopes which } \\
\text { are then translated to the regional and local level. However, } \\
\text { regions can generally transfer money between budget lines. }\end{array}$ & 0.5 & 1 \\
\hline $\begin{array}{l}\text { Staffing \& } \\
\text { outsourcing }\end{array}$ & $\begin{array}{l}\text { Regional and local offices can decide whether to outsource and } \\
\text { who to outsource to. }\end{array}$ & 0.5 & 0.5 \\
\hline Total & & 3 & 5 \\
\hline
\end{tabular}

\section{Avoiding the Downsides of Decentralisation}

193. We noted earlier in this report that although decentralisation may enhance programme outcomes, there may be unintended negative effects - for example a lack of standardisation in performance due to uneven quality in service delivery and problems with performance data. In addition, there are some elements of labour market policy - for example standards for occupations and professions and labour market information - that are necessary on a broader geographic basis in order to ensure free movement of workers and prevent negative spillovers from one country or region to another. Achieving the right balance between too much and too little decentralisation is a challenge faced by all OECD countries.

194. On the basis of the analysis in this report, Canada appears to have avoided many of these downsides. Although considerable authority and control has been retained at the P/T level, P/T governments are much closer to the regional and local level than Ottawa. The fact that P/Ts have retained control at the $\mathrm{P} / \mathrm{T}$ level is moderated by the significant amount of feedback within each $\mathrm{P} / \mathrm{T}$ system. The parameters of the federal funding agreements and performance measures are broad rather than prescriptive and ensure a level of standardisation across the country. P/Ts have their own sophisticated performance accountability systems that are now applied to labour market policy. They also have provincial/territoriallevel staff training and support systems in place that regional and local offices can take advantage of. Having this responsibility at a P/T level, with programme parameters and expectations the same across the $\mathrm{P} / \mathrm{T}$, reduces the potential for conflicts of interest and local protectionism that might occur at a very local level where government staff and clients know each other. Canadian P/Ts are at varying stages in terms of the level of sophistication and expertise of their staff in this particular policy domain. P/Ts such as Alberta and New Brunswick that have been providing these workforce supports and services for the past fourteen years have much to offer those jurisdictions that have only recently taken on an LMDA.

195. Compared to other federal political systems, however, institutional structures and processes to facilitate horizontal collaboration across Canada are weak. Without common benchmarks and comparable information, P/T governments are missing out on chances for policy learning from one another. There are many well developed models to facilitate horizontal collaboration that Canada could learn from. Since 1997 the European Employment Strategy (EES) has provided the 27 European Union (EU) member states with the tools to agree on a framework for action around common objectives and employment policy priorities. Involving direct participation from a wide array of social partners (industry and labour) as well as civil society organisations at both an EU and member state level, the EES has led to an increase in the 
European employment rate and a reduction in the long-term unemployment rate ${ }^{29}$. There is also a European Network of Heads of Public Employment Services, a network of private service providers, European-wide services to assist workers and employers wishing to cross borders, and annual European-wide exhibitions and conferences. The current European crisis notwithstanding it can still be useful to analyse such international practice to see whether there are any tools which could be effective in Canada and to consider how they could be adapted to work within Canada's rather different governance framework. Elsewhere in the United States the National Association of Workforce Boards supports their nearly 600 members through advocacy, training and technical assistance, communication, and promoting strategic partnerships for the advancement of the nation's workforce ${ }^{30}$ Each year they hold a national forum bringing leaders from workforce organisations, economic development, education, business, and others together to meet the particular US workforce challenges. Though labour market policy makers in Canada do have existing and functional fora for collaboration, they could expand on these efforts, drawing inspiration from other forms of pan-Canadian collaboration in the field of economic development and education as a source of ideas and models, two examples being the Agreement on Internal Trade and the New West Economic Partnership Trade Agreement.

\section{Conclusion and Next Steps}

196. One of the main interests in the OECD study has been to see how greater flexibility in the delivery of programmes can enable government labour market policy makers to collaborate more effectively with other actors, especially at the local level, in order to contribute to broad social and economic strategies. With the rising importance of the knowledge economy, it is important that policy makers recognise the role of human resources and skills in driving longer-term growth. Previous research in Canada (Giguère and Froy, 2009), has identified that labour market issues are sometimes neglected within local economic strategies in Canada, a finding corroborated by the current study. This is a situation replicated in many OECD countries, at least in part because local labour market officials do not have enough flexibility to adapt their programmes and policies to local strategic priorities.

197. While the devolution of greater powers regarding employment policy in Canada to the P/Ts has resulted in further flexibility at the regional and local levels, this does not seem to have translated significantly into enhanced strategic collaboration at these levels with other social and economic actors in the provinces studied. While labour market officials appear to have strong connections with individual businesses, and have established useful brokers (the BILs and LFDOs) to resolve short-term collective problems, it is less clear that they are working with economic development officials on longer term economic development strategies. Exceptions to this may be the work in New Brunswick between PETL and the Enterprise Agencies on tackling underemployment, and regional/local sector strategies (e.g. forestry) in Alberta .

198. The downturn has highlighted the fact that some local labour markets are more adaptable than others in response to external trends and shocks. In order for Canadian communities to be more adaptable,

See Ten Years of the European Employment Strategy available at http://ec.europa.eu/social/main.jsp?catId=738\&langId=en\&pubId=53\&furtherPubs $=y e s$ 
it is important that tomorrow's workforce is equipped with high-level generic skills, so that individuals can transfer between sectors, and innovate in response to changing markets (Froy and Giguère, 2010). This requires strong investment in early years and school-age education. At the same time, local people need to be able to access local employment and training systems throughout their working lives to adapt to new and emerging skills requirements through flexible systems of "life-long learning". Building a skilled and adaptable labour pool will not be simple in the future, as local communities become increasingly vulnerable to demographic change and rising mobility. Joined-up local employment and skills strategies will be key, which balance objectives such as the attraction and retention of talent, the upgrading of the skills of the low-qualified, the better utilisation of skills in the workplace and the integration of disadvantaged groups into the labour market. Such issues require strong collaboration between a number of local different actors, private, public and not-for-profit. They require a careful prioritisation of local resources, the adequate identification of opportunities and challenges through the sharing of information and data, and strong leadership to bring fragmented agencies behind common ambitions.

199. For successful horizontal collaboration to occur, national governments need to move away from hierarchical command and control models to networks of government agencies and non-government organisations. This seems to be what has happened in Canada. At the same time, government organisations at the sub-national level must have sufficient autonomy to respond to local circumstances and form partnerships so that resources can be exchanged (Eberts, 2009). In Canada, therefore, it may not be necessary to inject a great deal of further flexibility into the system. Rather, there needs to be support for better governance mechanisms which link labour market policy makers with other actors. Mechanisms for supporting mutual accountability between stakeholders at the local level, and for actions carried out within shared local strategies (like the Workforce Investment Boards in the United States, for example) should be encouraged. It will be important that such actions are based on an adequate base of disaggregated information and data. At the same time, in order for cross-sector strategies to work at the local level, it will be important for all the respective departments at the P/T and federal levels to buy-in to their success. It was clear from the study that in some cases valuable employment initiatives (for example to facilitate transportation of disadvantaged groups to employment areas) were blocked by inflexibility not in $\mathrm{P} / \mathrm{T}$ labour market policy but in other P/T departments. Joined-up thinking is therefore essential across all government levels. 


\section{Box 8. Summary for Canada}

1. Since 1996 and the devolution of active labour market programming to provincial and territorial governments through the Labour Market Development Agreements, how active labour market programs are designed, delivered and managed in Canada has changed substantially. Under the LMDAs, some provinces and territories in Canada show excellent practice in allowing local and regional officials room to manoeuvre in implementing labour market policy, within a framework which supports full accountability, and the collection of important quantitative data on results. In the provinces of Alberta and New Brunswick, for example, local and regional officials are empowered to choose the best mechanisms for delivering on priorities without over burdensome targets and regulations. P/Ts such as Alberta and New Brunswick that have been providing workforce supports and services for the past fourteen years have much to offer those Canadian jurisdictions that have only recently taken on a full transfer LMDA.

2. The type of management structure used in these cases is facilitated by the limited distance between the governance levels within the system, and the collegial and interactive management styles used, where officials at provincial/territorial, regional and local levels regularly meet and share information. The drawback to this system is that it relies on strategic policy direction from the P/T level, while planning at the local and regional levels is mainly operational and not strategic.

3. It is important that strategic directions are also taken at the level of local labour markets, given the considerable variation in labour market conditions which is evident in even small provinces such as New Brunswick. Such shared planning can ensure that actions are not only oriented to short-term needs, but also prepare communities for future economic trends and opportunities. It can also be supportive for local brokers (such as the LFDOs and BILs) when tackling more recurrent short-term problems.

4. For strategies to have real traction locally, it is useful to have systems of shared and horizontal accountability at the local level. New Brunswick is a good example of how this can be applied in practice, with regional employment officials reporting not only to their provincial PETL managers but also to the Enterprise Agencies. Such mechanisms could be substantiated further. Establishing local partnerships and boards within each $\mathrm{P} / \mathrm{T}$ which are accountable not only vertically but also to the local community can help facilitate this process (such as the Workforce Investment Boards in the United States).

5. Some rigidity still exists within the provincial systems studied, with provincial programmes being applied that do not match all local contexts. P/Ts could experiment with mechanisms used elsewhere in the OECD such as allocating programme regulation waivers when required to meet specific local challenges, or for rewarding innovative practices.

6. Post-devolution, there are 49 bilateral F-P/T agreements that govern labour market adjustment programs in Canada. Each of the different types of bilateral agreements - Labour Market Development Agreement, Labour Market Agreement, as well as the Labour Market Agreement for Persons with Disabilities and the Targeted Initiative for Older Workers (cost-shared programs) - have different policy parameters, allocation formulas and accountability frameworks, which each province and territory must track individually and account to the federal government for. Rationalisation of the existing array of F-P/T agreements would improve fairness in the system, allow for longer term strategic planning on a P/T as well as a panCanadian basis, and improve transparency and accountability to Canadian citizens.

7. Compared to other federal political systems, institutional structures and processes to facilitate horizontal collaboration across Canada between federal and $\mathrm{P} / \mathrm{T}$ governments and with non-government stakeholders are weak. Improved horizontal collaboration would provide opportunities for governments to discuss some of the current ambiguities and concerns around accountability relationships, funding formulas, timely reporting, and plans for the residual labour market programming that remains under federal control and delivery. There are many well developed international models available to provide ideas and techniques that the Canadian national employment service - now under the control of provincial and territorial governments - could learn from. 


\section{BIBLIOGRAPHY}

American Association of School Librarians (AASL) (1996), "Collaboration Brochure", based on research done by Winer and Ray 1994, Collaboration Handbook: Creating, Sustaining and Enjoying the Journey.

Bakvis, Herman and P. Aucoin (2000), Negotiating Labour Market Development Agreements, Canadian Centre for Management Development, Research No. 22, Ottawa.

Bakvis, Herman (2002), "Checkerboard Federalism? Labour Market Development Policy in Canada", in H. Bakvis and G. Skogstad (eds.), Canadian Federalism: Performance, Effectiveness and Legitimacy, Don Mills Ontario, Oxford University Press.

Banting, Keith (2005), "Canada Nation Building in a Federal Welfare State", in Obinger, Leibfried and Castles (eds.), Federalism and the Welfare State, New World and European Experiences, Cambridge University Press, Cambridge.

Bar Cendon, Antonio (2000), Accountability and Public Administration: Concepts, Dimensions, Developments, discussion paper.

Bruce, David (2009), Managing Labour Market Flexibility and Accountability: A Literature Review and Discussion Paper, prepared for Christian Boucher, HRSDC Canada

Canada (1940), Royal Commission on Dominion-Provincial Relations, Report, Book 1, Chaired by NewtonWesley Rowell and then by Joseph Sirois, Ottawa, King's Printer.

Canada (1996), Employment Insurance Act, available at www.servicecanada.gc.ca/eng/ei/legislation/ei_act_entry_page.shtml, accessed March 27, 2010.

Canada Employment Insurance Commission (2009), Employment Insurance Monitoring and Assessment Report, Publication Service, Human Resources and Skills Development Canada.

DC Strategic Management (2010), Flexibility and Accountability: an Overview of Provincial Labour Market Programs \& Projects, prepared for Human Resources and Skills Development Canada 22 January, 2010.

Eberts, Randal (2009), "The Role of Labour Market Policy in Horizontal Co-ordination", in S. Giguere and F. Froy (eds.), Flexible Policy for More and Better Jobs, OECD, Paris.

EKOS Research Associates (2008), Summative Evaluation of the Canadian Council on Learning, Final Report [online], 30 September 2008, available at: www.ccl-cca.ca/pdfs/corporatereports/CCLSummative-Evaluation-2008.pdf, accessed: 27 March 2009. 
Finance Canada (2007), Budget 2007, available at www.budget.gc.ca/2007/news-nouvelles/news-nouvelleseng.html, accessed February 25, 2010.

Giguère, S. and F. Froy (2009) Flexible Policy for More and Better Jobs, OECD Publishing, Paris.

Hunter, John (1993), The Employment Challenge, Federal Employment Policies and Programs 1900-1990, Public Affairs, Government of Canada.

Klassen, Thomas R. (1999), "Job Market Training: The Social Union in Practice", Policy Options, Vol. 20, $\mathrm{N}^{\circ} 10$, pp. 40-44.

Klassen, Thomas R. (2000), 'The Federal-Provincial Labour Market Development Agreements: Brave New Model of Collaboration?' in Federalism, Democracy and Labour Market Policy in Canada, Tom McIntosh, (ed), Montreal: McGill-Queen's University Press, pp. 159-203.

Klassen, Thomas and Donna Wood (2010), "Evolving Federal-provincial Accountability Regimes in Labour Market Policy", presented at the Feb 5-6, 2010 Understanding and Evaluating Intergovernmental Accountability Regimes: Canada in Comparative Perspective Conference, University of Toronto.

Lazar, Harvey (2002), Shifting Roles: Active Labour Market Policy in Canada under the Labour Market Development Agreements: A Conference Report, Canadian Policy Research Networks.

Lindsay Colin and Ronald McQuaid (2008), "Inter-agency Co-operation in Activation: comparing Experiences in three Vanguard 'Active' Welfare States", Social Policy and Society, Vol. 7, N 3, pp. 353-365, Cambridge University Press.

McGarvey, Neil (2001), "Accountability in Public Administration: A Multi-Perspective Framework of Analysis", Public Policy and Administration, Vol. 16, ํ2, pp. 17-28.

McIntosh, Tom (2000), "Is the Social Union Too Healthy? Re-thinking Labour Market Policy" Policy Options, April 2000, Institute for Research on Public Policy, Montreal.

Mosley, Hugh (2009), "The Trade-off between Flexibility and Accountability in Labour Market Policy", in S. Giguere and F. Froy (eds.), Flexible Policy for More and Better Jobs, OECD, Paris.

OECD (Organisation for Economic Development and Co-operation) (1994), OECD Jobs Study, Paris.

OECD (2003), Managing Decentralisation: A New Role for Labour Market Policy, OECD, Paris.

OECD (2007), Linking Regions and Central Governments: Contracts for Regional Development, OECD, Paris.

Froy, F and S. Giguère (2010a), Breaking out of Silos: Joining up Policy Locally, OECD Publishing, Paris.

Froy, F. and S. Giguère (2010b), Putting in Place Jobs that Last, OECD LEED Working Paper 2010/13, Paris. 
Poirier, Johanne, (2003), Keeping Promises in Federal Systems: the Legal Status of Intergovernmental Agreements with Special Reference to Belgium and Canada, Dissertation submitted for the Degree of $\mathrm{PhD}$, University of Cambridge, Faculty of Law.

Simeon, Richard (1978), Issues in Intergovernmental Relations, Ontario Economic Council.

Statistics Canada (2008), Economic Indicators, by Province and Territory, 13 June 2008, Ottawa.

Statistics Canada (2010), Labour Force Characteristics by Province, available at www.statcan.gc.ca/subjects-sujets/labour-travail/lfs-epa/t100312a3-eng.htm, accessed March 27, 2010.

Watt, Douglas and Natalie Gagnon (2005), The Skills Factor in Productivity \& Competitiveness: Canada's Sector Councils are Playing a Role, the Conference Board of Canada, available at www.conferenceboard.ca/Libraries/EDUC_PUBLIC/SectorCouncilLiteratureReview-eng.sflb, accessed March 27, 2010.

Wood Donna and Tom Klassen (2009), "Bilateral Federalism and Workforce Development Policy in Canada", Canadian Public Administration, Vol. 52, №2, July 2009, pp. 249-270. 


\section{ANNEX A. VENICE ACTION STATEMENT ON ENHANCING FLEXIBILITY IN THE MANAGEMENT OF LABOUR MARKET POLICY}

\section{Preamble}

We, the participants of the high level conference on 'Decentralisation and Co-ordination: The Twin Challenges of Labour Market Policy', held in Venice on 17-19 April 2008, propose the following Action Statement, which aims to underline the importance of enhancing flexibility in the management of labour market policy in order better to reconcile national and local goals.

At a time when human resources are so much at the heart of economic growth, it has become urgent to review the organisation of employment policy so that it is better able to respond to the opportunities and threats experienced by localities in a knowledge-based economy. Working together, we hope to make new advances on the critical issue of balancing national policy goals and local concerns in a way which reaps maximum benefits from globalisation.

\section{Background: A changing role for labour market policy}

In a globalised economy, where both capital and labour are highly mobile and technology evolves rapidly, workforce development institutions have a key role to play in improving prosperity as well as working and living standards. Human resources are a fundamental source of economic development in a knowledge-based economy. Policy makers within the field of labour market policy and training have a major contribution to make, not only in providing the pool of skills which the economy needs locally, but also in fostering innovation, entrepreneurship and social cohesion.

The decentralisation which has taken place in many OECD countries in employment policy over the last 10 years has helped decision-making to occur closer to the 'reality on the ground', but there is still some way to go before local labour market agencies have the capacity to make a significant contribution to broader local strategic goals. Achieving local objectives often requires cross-working between a number of different policy areas (such as employment, vocational training and economic development) to achieve integrated local strategies. This depends on the ability of local policy makers to better align their policies and services, which in turn depends on the flexibility they have to influence the delivery of policies and services. By providing such flexibility, national authorities can make it possible for local actors to work together on the complex and cross-cutting labour market issues which affect their particular community, to innovate as necessary and to adapt policies to local needs.

A major factor restricting the ability of national actors to make flexibility available in the management of labour market policy at the local level is the need to retain accountability. Indeed, this is one of the most difficult challenges faced by decentralised frameworks. Proper decentralisation implies a sharing of responsibility for decision-making at the local level among a number of actors, and agreement on an 
accountability framework politically acceptable to the various government levels. It requires partnership working among different stakeholders and between the national and local levels.

Capacity and intelligence are essential companions to flexibility at the local level. Co-ordinating labour market policy with economic development beyond the fulfilment of short-term business needs requires an understanding of both local and global economic conditions and an ability to help business managers avoid future bottlenecks, skills gaps and deficiencies in productivity. Joint and integrated planning requires locally-assembled data and expertise which can support the establishment of common strategic objectives and the better management of policy conflicts and trade-offs. Thus, for governments, building capacities and ensuring the availability of disaggregated data should also be central elements in any strategy to ensure the success of decentralisation.

\section{Proposed Actions}

We, the participants at the Venice high-level conference therefore invite national, regional and local level actors in the field of employment to work together with the aim to:

a. Inject flexibility into the management of labour market policy. It should be possible for the local level to give strategic orientations to the implementation of programmes. Local staff should have the ability to make decisions on the orientation of public programmes and services, in addition to achieving predetermined objectives.

b. Establish an overarching management framework which embeds local flexibility. Employment policy should be managed in a way which supports greater local differentiation while still paying attention to aggregate impacts at the national level. In particular, targets should be negotiated with the local level in order to ensure that they meet local strategic needs, while being embedded in a wider framework which ensures that aggregate national policy goals continue to be met.

c. Build strategic capacity. Enhancing local capacities becomes particularly important in this context, as strategies for human resources development must be integrated and matched to the economic reality on the ground. Staff within labour market agencies should have a strong knowledge of local business practices, local economic conditions, industry developments, and appropriate methods to identify skills gaps and deficiencies in local economic sectors. They should also develop the analytical skills necessary to use this knowledge as a basis for developing broad strategic orientations locally.

d. Build up local data and intelligence. Building an understanding of economic and labour market conditions demands, as a prerequisite, refined data collection and analysis as well as expertise in a wide variety of fields. The capacity to gather data locally and organise it in a way which can support strategic planning exercises is critical. The national level can support this process by ensuring that data is disaggregated to the local level and by making available analytical tools which can be adapted to local circumstances.

e. Improve governance mechanisms. Labour market agencies should collaborate effectively with business, trade unions, civil society, education institutions, research centres, economic development agencies and local authorities. There is no governance mechanism which fits all institutional frameworks, but partnerships have a certain value in bringing different stakeholders together to develop appropriate and realistic strategies.

f. Improve administrative processes. Aligning policies through institutional reform such as decentralisation is a difficult challenge. In large countries, with complex distributions of power, a 
perfect match may always seem just beyond reach. A wide-scale review of how administrations function, cooperate and manage policies is required to support better collaboration between different administrative layers and between different policy institutions. This is particularly important given that the new, broader goals for human resources development cut across a number of different policy areas. 


\section{ANNEX B. METHODOLOGY FOR ASSESSING LOCAL FLEXIBILITY IN LABOUR MARKET POLICY IN OECD COUNTRIES}

In 2008, the OECD LEED Programme carried out an international study of 25 countries as to the local flexibility available in the management of labour market policy (Giguère and Froy, 2009). The OECD looked at the degree of flexibility available to local employment agencies operating at Territorial Level 3 (serving populations of approximately 800,000 or below) in six main areas: designing programmes; allocating budgets; defining target groups; setting performance criteria; collaborating with other actors; and outsourcing.

The OECD scored countries against the degree of flexibility available and used the results of the research to allocate an overall index of local flexibility between 0 and 5 for each country (see Table A1 below), which was used to perform an international comparison. In each case, one of three scores was awarded for each country (1.0 flexibility, 0.5 some flexibility, 0 no flexibility). All accountability mechanisms were given equal weight in the resulting analysis, except for (e) collaboration and (f) outsourcing which were allocated a total possible score of 0.5 . Where a country did not use a particular management tool in managing regional or local offices (for example outsourcing), this was taken into account using a normalisation process.

Table A1: Scoring mechanism used by the OECD (2008)

\begin{tabular}{|l|l|l|}
\hline Management area & Criteria & Score \\
\hline \multirow{5}{*}{ Programme design } & No flexibility & 0 \\
\cline { 2 - 3 } & Local offices are consulted & 0.5 \\
\cline { 2 - 3 } & Local offices design employment strategies & 0.5 \\
\cline { 2 - 3 } & Local offices can choose mix of programming & 0.5 \\
\cline { 2 - 3 } & Local offices involved in programme design & 1 \\
\hline \multirow{5}{*}{ Budgets } & No flexibility & 0 \\
\cline { 2 - 3 } & Special funding pot available for local initiatives & 0.5 \\
\cline { 2 - 3 } & Can move funding between budget lines. & 0.5 \\
\cline { 2 - 3 } & A block grant is available. & 1 \\
\hline \multirow{5}{*}{ merformance } & No flexibility & 0 \\
\cline { 2 - 3 } & Some freedom to decide on eligible target groups & 0.5 \\
\cline { 2 - 3 } & Local offices set eligibility criteria & 1 \\
\hline \multirow{3}{*}{ Outsourcing } & No flexibility & 0 \\
\cline { 2 - 3 } & Local offices negotiate performance targets & 0.5 \\
\cline { 2 - 3 } & Local offices set performance targets & 1 \\
\hline \multirow{3}{*}{ Collaboration } & No flexibility & 0 \\
\cline { 2 - 3 } & Local offices involved in deciding who to outsource to/what to outsource. & 0.5 \\
\hline & No flexibility & 0 \\
\cline { 2 - 3 } & Local offices can choose who they collaborate with & 0.5 \\
\hline
\end{tabular}


